\title{
Spectral actinic flux in the lower troposphere: measurement and 1-D simulations for cloudless, broken cloud and overcast situations
}

\author{
A. Kylling ${ }^{1}$, A. R. Webb ${ }^{2}$, R. Kift ${ }^{2}$, G. P. Gobbi ${ }^{3}$, L. Ammannato ${ }^{3}$, F. Barnaba ${ }^{3}$, A. Bais ${ }^{4}$, S. Kazadzis ${ }^{4}$, M. Wendisch ${ }^{5}$, \\ E. Jäkel ${ }^{5}$, S. Schmidt ${ }^{5}$, A. Kniffka ${ }^{6}$, S. Thiel ${ }^{7}$, W. Junkermann ${ }^{7}$, M. Blumthaler ${ }^{8}$, R. Silbernagl ${ }^{8}$, B. Schallhart ${ }^{8}$, \\ R. Schmitt ${ }^{9}$, B. Kjeldstad ${ }^{10}$, T. M. Thorseth ${ }^{10}$, R. Scheirer ${ }^{11}$, and B. Mayer ${ }^{11}$ \\ ${ }^{1}$ Norwegian Institute for Air Research, Kjeller, Norway; now at St. Olavs Hospital, Trondheim University Hospital, Norway \\ ${ }^{2}$ Physics Department, University of Manchester Institute of Science and Technology, Manchester, UK \\ ${ }^{3}$ Istituto di Scienze dell'Atmosfera e del Clima-CNR, Roma, Italy \\ ${ }^{4}$ Laboratory of Atmospheric Physics Aristotle University of Thessaloniki, Greece \\ ${ }^{5}$ Leibniz-Institut für Troposphärenforschung, Leipzig, Germany \\ ${ }^{6}$ Institut für Meteorologie, Universität Leipzig, Leipzig \\ ${ }^{7}$ Institut für Meteorologie und Klimaforschung, Garmisch-Partenkirchen, Germany \\ ${ }^{8}$ Institute of Medical Physics, University of Innsbruck, Innsbruck, Austria \\ ${ }^{9}$ Meteorologie Consult GmbH, Germany \\ ${ }^{10}$ Department of Physics, Norwegian University of Science and Technology, Trondheim \\ ${ }^{11}$ Deutsches Zentrum für Luft- und Raumfahrt (DLR), Oberpfaffenhofen, Wessling, Germany
}

Received: 25 January 2005 - Published in Atmos. Chem. Phys. Discuss.: 10 March 2005

Revised: 21 June 2005 - Accepted: 27 June 2005 - Published: 3 August 2005

\begin{abstract}
In September 2002, the first INSPECTRO campaign to study the influence of clouds on the spectral actinic flux in the lower troposphere was carried out in East Anglia, England. Measurements of the actinic flux, the irradiance and aerosol and cloud properties were made from four ground stations and by aircraft. The radiation measurements were modelled using the uvspec model and ancillary data. For cloudless conditions, the measurements of the actinic flux were reproduced by $1-\mathrm{D}$ radiative transfer modelling within the measurement and model uncertainties of about $\pm 10 \%$. For overcast days, the ground-based and aircraft radiation measurements and the cloud microphysical property measurements are consistent within the framework of 1-D radiative transfer and within experimental uncertainties. Furthermore, the actinic flux is increased by between $60-100 \%$ above the cloud when compared to a cloudless sky, with the largest increase for the optically thickest cloud. Correspondingly, the below cloud actinic flux is decreased by about 55$65 \%$. Just below the cloud top, the downwelling actinic flux has a maximum that is seen in both the measurements and the model results. For broken clouds the traditional cloud fraction approximation is not able to simultaneously reproduce the measured above-cloud enhancement and below-cloud reduction in the actinic flux.
\end{abstract}

Correspondence to: A. Kylling

(arve.kylling@helse-sunnmore.no)

\section{Introduction}

Clouds exhibit large variations in their optical properties on both small and large scales. Furthermore, their shapes have an infinite multitude of realisations. Thus, due to their nature, clouds are a challenge to treat realistically in radiative transfer calculations. Clouds are important for the radiative energy budget of the Earth (Ramanathan et al., 1989), and they influence the amount of radiation available for photochemistry (Madronich, 1987). For example, the reflection of radiation by clouds shifts the photostationary state relationship (NO-O $-\mathrm{NO}_{2}$ ) towards $\mathrm{NO}$, thereby favoring $\mathrm{NO}$ to $\mathrm{NO}_{2}$ conversions by other compounds than $\mathrm{O}_{3}$. This effectively increases $\mathrm{O}_{3}$ formation rate in the upper troposphere. Other photolysis rates are affected as well, and these changes may either add to or counteract to the chemical effect of enhanced $\mathrm{NO}_{2}$ photolysis (Thompson, 1984). Clouds may also both decrease and increase the amount of biologically harmful UV irradiance at Earth's surface (e.g. Mims and Frederick, 1994).

The simplest way to introduce clouds in radiative transfer models is to approximate them as a single, homogeneous layer. This approach is and has been used for a number of studies. The limitation of this approximation is evident, especially when considering broken-cloud conditions. However, apparently horizontally homogeneous clouds may exhibit large variations, and the corresponding radiative effects may locally be large (Cahalan et al., 1994). 
Experimental investigations of the effect of clouds on the radiation which are of importance for the photochemistry of the atmosphere have been carried out by several groups. Many of these have measured the photolysis frequencies $\mathrm{J}\left(\mathrm{O}^{1} \mathrm{D}\right)$ and $\mathrm{J}\left(\mathrm{NO}_{2}\right)$, while rather few have investigated the spectral actinic flux. The spectral actinic flux is needed to calculate the photolysis frequency (Madronich, 1987) and is also the quantity calculated by radiative transfer models used in photochemistry applications.

The $\mathrm{J}\left(\mathrm{O}^{1} \mathrm{D}\right)$ photolysis frequency was measured by Junkermann (1994) from a hangglider above snow surfaces and within and above stratiform clouds. The photolysis frequency increased by a factor of 2 above the cloud compared to cloudless conditions. Snow on the ground increased the cloudless photolysis frequency, with the increase being largest for conditions with high visibility. Vilà-Guerau de Arellano et al. (1994) made tethered-balloon measurements of the actinic flux integrated between 330 and $390 \mathrm{~nm}$ in cloudy conditions. They found excellent agreement between a delta-Eddington radiative transfer model and the measurements during overcast conditions. For partial cloudiness ( $\leq 7$ oktas), there was a larger disagreement between the measurements and the model simulations (their Fig. 2). Kelley et al. (1995) reported actinometer measurements of the $\mathrm{J}\left(\mathrm{NO}_{2}\right)$ photolysis frequency during cloudless and cloud conditions. They reported a $\mathrm{J}\left(\mathrm{NO}_{2}\right)$ in-cloud enhancement of up to $58 \%$. The effect of clouds on $\mathrm{J}\left(\mathrm{NO}_{2}\right)$ was also discussed by Lantz et al. (1996), and they proposed a simplified cloud model to explain $\mathrm{J}\left(\mathrm{NO}_{2}\right)$ values that exceeded clear sky values during partly cloudy conditions. Matthijsen et al. (1998) converted UV irradiance aircraft measurements to $\mathrm{J}\left(\mathrm{O}^{1} \mathrm{D}\right)$ photolysis frequencies. They subsequently used cloud microphysical measurements and radiative transfer calculations to investigate the effect of clouds on the photolysis frequency $\mathrm{J}\left(\mathrm{O}^{1} \mathrm{D}\right)$ and the $\mathrm{OH}$ concentration. The modelled profile of $\mathrm{OH}$ was compared with measurements and generally good agreement was found for rather complex cloud conditions. Früh et al. (2000) compared aircraft measurements of $\mathrm{J}\left(\mathrm{NO}_{2}\right)$ with model simulations for clear and cloudless situations for altitudes up to $2.5 \mathrm{~km}$. Cloud input to the model was provided by simultaneous measurements of thermodynamic, aerosol particle, and cloud drop properties. For the cases studied, cloudless and total cloud cover, the measurements and model simulations agreed to within $10 \%$. Shetter and Müller (1999) made measurement of the spectral actinic flux, which was used to calculate various photolysis frequencies. For flights over the Pacific Ocean, photolysis frequency enhancements due to clouds of about a factor of 2 over cloudless values were reported. Crawford et al. (2003) and Monks et al. (2004) investigated the cloud impacts on surface UV spectral actinic flux during cloudless and cloudy situations. Wavelength-dependent enhancements and reductions compared to a cloudless sky were observed when during partial cloud cover the sun is unobscured and obscured, respectively.
On the theoretical side, numerous model studies have investigated the 3-D effects of clouds. Most of these have focused on cloud albedo and energy budget studies, cloud absorption anomaly (Stephens and Tsay, 1990) and satellite retrievals (Chambers et al., 1997). Also, they mostly examine how inhomogeneities change radiance and flux values at fixed locations. A more generally descriptive framework has been developed by Várnai and Davies (1999), who consider how individual photons are influenced by heterogeneities as they move along their paths within a cloud layer. Rather few studies have looked at the effect on the actinic flux. The first study of 3-D cloud effects on the actinic flux was made by Los et al. (1997). They considered hexagonal clouds for various cloud fractions with a Monte Carlo model. Molecular and aerosol scattering was not included in their simulations. Trautmann et al. (1999) investigated the spatial distribution of the actinic flux for 2D clouds in an aerosolfree atmosphere with both a Monte Carlo model and the Spherical Harmonic Discrete Ordinate Method (SHDOM, Evans, 1998). Among their conclusions was the finding that the plane-parallel approximation generally underestimates the photodissociation coefficients in and below the cloud. Brasseur et al. (2002) performed 3-D model investigations of the impact of a deep convective cloud on photolysis frequencies and photochemistry. The radiative impacts were quantified with SHDOM, and enhancement factors of the local spectral actinic flux relative to the incoming flux were calculated. Increases of the actinic flux relative to the incoming flux of 2 to 5 , compared to cloudless values, were found above, at the top edge and around the deep convective cloud. This enhanced actinic flux produced enhanced $\mathrm{OH}$ concentrations (120-200\%) in the upper troposphere above the clouds and changes in ozone production $(+15 \%)$. It is noted that the full 3-D radiative transfer problem may be solved by a number of different methods. While all are computationally demanding, the 3-D problem is nevertheless solvable. The main challenge with $3-\mathrm{D}$ radiative transfer in the presence of clouds is to specify the cloud input.

The earlier experimental studies of the influence of clouds on the actinic flux and photolysis frequencies have either been part of a larger campaign with a different main focus and/or been performed by a single platform. As part of the influence of clouds on the spectral actinic flux in the lower troposphere (INSPECTRO) project, a dedicated measurement campaign was carried out with the aim to characterize the cloud, aerosol and radiation within a well defined area. In the following, the measurements are described first, followed by a brief description of the radiative transfer model used for the data interpretation. The method used to derive a cloud optical depth is discussed next. This is followed by a discussion of the measured and simulated spectral actinic fluxes under cloudless, overcast and broken cloud conditions. Finally the paper is summarized. 
Table 1. Location of the ground stations and the type of measurements made at the respective stations. For description of the instrumentation see Table 2.

\begin{tabular}{llll}
\hline Place & Latitude & Longitude & measurements \\
\hline Weybourne & $525702 \mathrm{~N}$ & $010718 \mathrm{E}$ & actinic flux (ATI), irradiance (ATI), lidar, chemistry \\
Beeston Regis & $525615 \mathrm{~N}$ & $011600 \mathrm{E}$ & actinic flux (GBM), irradiance (GBM) \\
Briston & $525030 \mathrm{~N}$ & $010500 \mathrm{E}$ & actinic flux (DEG), irradiance (DEG,GRT) \\
Aylsham & $524620 \mathrm{~N}$ & $011350 \mathrm{E}$ & actinic flux (DED), irradiance (NTN) \\
\hline
\end{tabular}

\section{Measurements}

The INSPECTRO campaign took place in East Anglia, England, September 2002. It began with a one-week intercomparison of all radiation instrumentation at the Weybourne station. The following three weeks the instruments were in operation at four different stations located such as to cover a grid of approximately $12 \times 12 \mathrm{~km}^{2}$, see Table 1 .

Aircraft measurements were carried out on 11 of the total of 20 campaign days. A list over all instruments utilized in the present study is given in Table 2. Further details are provided below.

\subsection{Ground measurements}

Ground measurements were made at four locations northeast of the international airport of Norwich. Two of the stations, Briston and Aylsham, were inland, while the other two, Weybourne and Beeston Regis, were on the coast (see Table 1). All stations made irradiance and downwelling actinic flux measurements. Both scanning and diode array spectrometers were in use (see Table 2). The instruments and their calibration have been described earlier in connection with the actinic flux determination from measurements of irradiance (ADMIRA) project by Webb et al. (2002) and references therein. At the start of the campaign, an instrument comparison was performed in Weybourne with all instruments present. The Joint Research Centre (JRC) travelling reference spectroradiometer performed irradiance measurements during the intercomparison and also travelled to all locations afterwards to check the stability of each instrument and the possible effects of transportation. Typically, the agreement between the various independently calibrated instruments was within $\pm 10 \%$, which is within their measurement uncertainties of about $\pm 5 \%$.

At Weybourne the Vehicle-Mounted Lidar System (Gobbi et al., 2000, VELIS) was in operation throughout the campaign. Measurements from VELIS were used to retrieve the aerosol backscatter and extinction profiles at $532 \mathrm{~nm}$ using the methods described in Gobbi et al. (2004) and Barnaba and Gobbi (2004). These aerosol optical properties were used as input to radiative transfer simulations. In addition, VELIS provided cloud bottom altitude and cirrus cloud information.

\subsection{Airborne platforms}

During the INSPECTRO campaign, the Partenavia P68C aircraft operated by the Leibniz-Institute for Tropospheric Research (IfT) measured the downwelling and upwelling irradiances and actinic fluxes. The irradiances are measured by the so-called Albedometer (Wendisch et al., 2001; Wendisch and Mayer, 2003; Wendisch et al., 2004). The actinic fluxes are measured by the actinic flux density meter (AFDM) described by Jäkel et al. (2005). In addition to the radiation instrumentation, the IfT-Partenavia has various instruments for measurement of particle size distribution and concentrations. A Particle Volume Monitor (PVM) was used to measure the liquid water content, with an error of about $\pm 10 \%$. The water droplet effective radius, defined as the ratio of the third to the second moment of the droplet size distribution, was deduced from Fast Forward Scattering Spectrometer Probe (Fast-FSSP) measurements, with an error of about $\pm 4 \%$. Finally, the aircraft was equipped with sensors for measurement of standard avionic and meteorological parameters.

Albedo measurements in the UV and visible were performed by the Cessna 182 light aircraft from the University of Manchester Institute of Science and Technology. A temperature-stabilised Optronic 742 wavelength-scanning spectroradiometer measured the up- and downwelling irradiances at selected wavelengths. From the irradiance measurements at various altitudes, the albedo of the surface below was derived. In addition, the albedo at 312 and $340 \mathrm{~nm}$ was deduced from measurements of the NILU-CUBE instrument (Kylling et al., 2003a) suspended below a hot air balloon. These albedo measurements are described by Webb et al. (2005).

\section{Radiative transfer model}

The uvspec model from the libradtran package (http://www. libradtran.org and Mayer and Kylling , 2005) was used to simulate the measurements. Input to the model are profiles of the atmosphere taken from the U.S. standard atmosphere (Anderson et al., 1986). The aerosol optical depth profile was taken from the VELIS measurements. The aerosol single-scattering albedo and asymmetry factor were set to 0.98 and 0.75 , respectively. Changes in the solar zenith angle during a single measurement scan are accounted for. 
Table 2. Instruments located at the various stations. Additional instrumentation were also present, but not used in this study.

\begin{tabular}{|c|c|c|c|}
\hline Acronym & Place & Instrument & Measurements \\
\hline \multicolumn{4}{|c|}{ Ground-based } \\
\hline VELIS & Weybourne & polarization lidar & $\begin{array}{l}\text { Particle backscatter and extinction at } \\
532 \mathrm{~nm} \text {. Discrimination solid/liquid/mixed } \\
\text { phase of clouds/aerosols. Observational } \\
\text { range } 150 \mathrm{~m}-25 \mathrm{~km} \text {, resolution } 75 \mathrm{~m} \text {. }\end{array}$ \\
\hline ATI & Weybourne & Bentham DTM300 & $\begin{array}{l}\text { Actinic flux, irradiance, direct irradiance } \\
\text { spectra. Scanning } 290-600 \mathrm{~nm} \text { with } 0.5 \mathrm{~nm} \\
\text { step in 3-4 min. }\end{array}$ \\
\hline DEG & Briston & Bentham DTM300 & $\begin{array}{l}\text { Actinic flux and irradiance } \\
\text { spectra. Scanning } 290-600 \mathrm{~nm} \text { with } 0.5 \mathrm{~nm} \\
\text { step in about } 6 \mathrm{~min} .\end{array}$ \\
\hline GRT & Briston & Brewer Mark III & $\begin{array}{l}\text { Global and direct irradiance spectra. } \\
\text { Scanning } 290-365 \mathrm{~nm} \text { with } 0.5 \mathrm{~nm} \text { step } \\
\text { in } 6-7 \mathrm{~min} \text {. }\end{array}$ \\
\hline NTN & Aylsham & Bentham DM150 & $\begin{array}{l}\text { Global and direct irradiance spectra. } \\
\text { Scanning } 290-550 \mathrm{~nm} \text { with } 0.5 \mathrm{~nm} \text { step } \\
\text { in } 10-12 \mathrm{~min} \text {. }\end{array}$ \\
\hline JRC & $\begin{array}{l}\text { travelling } \\
\text { reference }\end{array}$ & Bentham DM150 & $\begin{array}{l}\text { Global and direct irradiance spectra } \\
\text { scanning from } 290-500 \mathrm{~nm} \text { in } 5-6 \mathrm{~min} \text {. }\end{array}$ \\
\hline DED & Aylsham & Diode array & Actinic flux spectrum covering \\
\hline & & & $\begin{array}{l}290-700 \mathrm{~nm} \text { with } 0.5 \mathrm{~nm} \text { step, FWHM about } 2.1 \mathrm{~nm} \text {. } \\
\text { Time resolution about } 10 \mathrm{~s} \text {. }\end{array}$ \\
\hline GBM & $\begin{array}{l}\text { Beeston- } \\
\text { Regis }\end{array}$ & Bentham DTM300 & $\begin{array}{l}\text { Actinic flux and irradiance spectra. } \\
\text { Scanning } 290-500 \mathrm{~nm} \text { with } 0.5 \mathrm{~nm} \text { step } \\
\text { in about } 7 \mathrm{~min} \text {. }\end{array}$ \\
\hline \multicolumn{4}{|c|}{ Airborne } \\
\hline AFDM & $\begin{array}{l}\text { Partenavia } \\
\text { Leipzig }\end{array}$ & Diode array & $\begin{array}{l}\text { Down- and upwelling actinic flux spectra } \\
\text { between } 305-700 \mathrm{~nm} \text {, FWHM about } 2.5 \mathrm{~nm} \text {. }\end{array}$ \\
\hline ALB & $\begin{array}{l}\text { Partenavia } \\
\text { Leipzig }\end{array}$ & Diode array & $\begin{array}{l}\text { Down- and upwelling irradiance spectra } \\
\text { between } 350-1000 \mathrm{~nm}, \text { FWHM about } 2.5 \mathrm{~nm} \text {. }\end{array}$ \\
\hline PVM & $\begin{array}{l}\text { Partenavia } \\
\text { Leipzig }\end{array}$ & $\begin{array}{l}\text { Particle Volume } \\
\text { Monitor }\end{array}$ & Drop effective radius, liquid water content \\
\hline Fast-FSSP & $\begin{array}{l}\text { Partenavia } \\
\text { Leipzig }\end{array}$ & $\begin{array}{l}\text { Forward Scattering } \\
\text { Spectrometer Probe }\end{array}$ & $\begin{array}{l}\text { Drop size distribution, } \\
\text { drop concentration }\end{array}$ \\
\hline UMIST & $\begin{array}{l}\text { Cessna } \\
182\end{array}$ & Optronic 742 & $\begin{array}{l}\text { Down- and upwelling irradiance spectra } \\
\text { between } 300-500 \mathrm{~nm}, \text { FWHM about } 1.5 \mathrm{~nm} \text {. }\end{array}$ \\
\hline
\end{tabular}

Temperature-dependent ozone cross sections are taken from Bass and Paur (1985). The ozone column was taken either from the GRT Brewer instrument or the Earth Probe Total Ozone Monitoring Spectrometer (TOMS) (Table 3). The ozone column was assumed to be constant over the measurement area. For days 257 and 261 the TOMS total ozone column was used as clouds prevented measurements with the GRT Brewer. For the other days the GRT measurements were utilized. The uncertainty in the total ozone column measurements are about $2 \%$ for the Brewer under cloudless conditions and about $4 \%$ for the TOMS. The ozone measurement did not always coincide in time with the radia- tion measurement, thus increasing the uncertainty in the total ozone column value used for the radiative transfer calculations. With these uncertainties in mind, $10 \mathrm{DU}$ was added to the GRT total ozone column to achieve the agreement between model and measurement shown in Sect. 5.1.1. This decreases the model values by about $6 \%$ at $305 \mathrm{~nm}$, but has negligible effect on the integrated shortwave UV (305-320 nm) and cloud effects presented below. The Rayleigh scattering cross section is calculated according to the formula of Nicolet (1984). The surface albedo was deduced from aircraft measurements reported by Webb et al. (2005). Here the values in their Table 1 are adopted and adjusted down to be at 
Table 3. Days analysed. Ozone values are from the ground-based GRT Brewer or the Earth Probe TOMS. Missing data are indicated by a $\mathrm{St}=$ stratus, $\mathrm{Cu}=$ cumulus, $\mathrm{Ci}=$ cirrus. Cloud cover is given in oktas. In the table $3 / 8 \mathrm{Ci}$ west is 3 oktas of cirrus located in the western part of the sky and $1 / 8$ at $\mathrm{Cu} 1000 \mathrm{~m}$ indicates 1 okta of Cumulus clouds above $1000 \mathrm{~m}$.

\begin{tabular}{|c|c|c|c|c|c|c|}
\hline Date & $\begin{array}{l}\text { Day of } \\
\text { year }\end{array}$ & $\begin{array}{l}\text { Start-end } \\
\text { flight (UTC) }\end{array}$ & $\begin{array}{l}\max -\min \\
\text { sza (degrees) }\end{array}$ & $\begin{array}{l}\text { Ozone } \\
\text { TOMS (DU) }\end{array}$ & $\begin{array}{l}\text { Ozone } \\
\text { GRT (DU) }\end{array}$ & Comments \\
\hline 12.9 & 255 & $1242-1505$ & $62.8-49.9$ & 269 & 271 & cloudless \\
\hline \multirow[t]{2}{*}{13.9} & 256 & $1020-1050$ & $52.7-50.8$ & 257 & 264 & partly cloudy \\
\hline & & $1320-1522$ & $65.4-52.5$ & & & partly cloudy \\
\hline 14.9 & 257 & $1005-1231$ & $54.2-49.2$ & 303 & - & $8 / 8 \mathrm{St} 610-850 \mathrm{~m}$, no $\mathrm{Ci}$ \\
\hline 18.9 & 261 & $1239-1358$ & $57.8-52.3$ & 273 & - & $\begin{array}{l}\text { inhomogeneous St } 1400-1700 \mathrm{~m} \text { and } \mathrm{Cu} 460-610 \mathrm{~m} \text {, } \\
4 / 8-8 / 8 \mathrm{Ci}\end{array}$ \\
\hline 20.9 & 263 & $1230-1412$ & $60.0-42.5$ & 284 & 280 & $8 / 8 \mathrm{St} 1800-1950 \mathrm{~m}, 3 / 8 \mathrm{Ci}$ west, $1 / 8 \mathrm{Cu}$ at $1000 \mathrm{~m}$ \\
\hline
\end{tabular}

the lower error margin for the lowest wavelengths. The radiative transfer equation is solved by the discrete ordinate algorithm developed by Stamnes et al. (1988). This algorithm has been modified to account for the spherical shape of the atmosphere using the pseudo-spherical approximation (Dahlback and Stamnes, 1991). The pseudo-spherical radiative transfer equation solver was run in 16-stream mode. The extraterrestrial spectrum was adopted from several sources. Between 280 and $407.8 \mathrm{~nm}$, the Atlas 3 spectrum shifted to air wavelengths was used. Atlas 2 (Woods et al., 1996) was used between 407.8 and $419.9 \mathrm{~nm}$. Above $419.9 \mathrm{~nm}$, the solar spectrum in the MODTRAN 3.5 radiation model was used (Anderson et al., 1993). The uncertainty in the model simulations is for a given condition controlled by the uncertainties in the input parameters. The effect of uncertainties in input parameters on the accuracy of model simulations have been investigated by Schwander et al. (1997) and Weihs and Webb (1997). Here it is noted that the present model for irradiances agree with other models and measurements to within $\pm 3-5 \%$ under well-defined cloudless conditions (Mayer et al., 1997; Kylling et al., 1998; Van Weele et al., 2000). Comparison between the model and the albedometer (ALB) have been reported by Wendisch and Mayer (2003) to be within $\pm 10 \%$ for the downwelling irradiances. The model agrees with groundbased actinic flux measurements within $\pm 6 \%$ (Bais et al., 2003), and airborne actinic flux measurements within $\pm 5 \%$ for altitudes between 3000-12000 m (Hofzumahaus et al., 2002).

\section{Cloud optical depth}

To quantify the effect of clouds on the actinic flux, a measure is needed of the cloud optical depth over the domain. From the surface irradiance measurements, the effective cloud optical depth was derived using the method of Stamnes et al. (1991). The effective cloud optical depth is determined by comparing the irradiance at a wavelength where absorption by ozone is negligible with model-generated irradiances for various cloud optical depths. It is assumed that the cloud is vertically homogeneous and that the effective droplet radius is $10 \mu \mathrm{m}$. By effective cloud optical depth is meant the optical depth that when used in the model best reproduces the measurements. Hence, the effective cloud optical depth includes both aerosol and cloud optical depths. Mostly due to northerly winds, both lidar and sunphotometers showed very low aerosol abundances throughout the campaign, with typical 500-nm aerosol optical depth values ranging between 0.05 and 0.15 . Hence, it may be assumed that the estimated effective cloud optical depths are not significantly affected by aerosols. In addition to the cloud optical depth, the cloud transmittance is derived by taking the ratio of the measured irradiance to the cloudless modelled irradiance. Except for the GRT spectroradiometer, a wavelength region centered at $380 \mathrm{~nm}$ and weigthed with a triangular function with a bandpass of $5 \mathrm{~nm}$ was used to estimate the effective cloud optical depth and the cloud transmittance. For the GRT instrument, a wavelength region centered at $350 \mathrm{~nm}$ was used.

The derivation of a cloud optical depth by this method is based on a direct comparison between measured and modelled irradiances. Hence, absolute agreement between the measurements and simulations must be ensured. In Fig. 1 examples are shown of measured and simulated spectra during cloudless conditions. The agreement between the measurements and the model simulations is within the uncertainties associated with the measurements and the simulations and is of the same magnitude as that reported earlier by Mayer et al. (1997); Kylling et al. (1998) and Van Weele et al. (2000) for similar conditions. Differences between the measurements and the simulations of $\pm 5 \%$ gives uncertainties of around $10 \%$ in the derived cloud optical depth. The uncertainty is largest for optically thin clouds.

The cloud optical depths derived from the ground measurements were compared with in situ aircraft data for two days, days 257 and 263, when the sky was overcast. On both days the aircraft made several triangular patterns at constant altitudes above the ground stations and some profiles. Here attention is paid to the profile measurements. The liquid water content and the effective radius measured during 

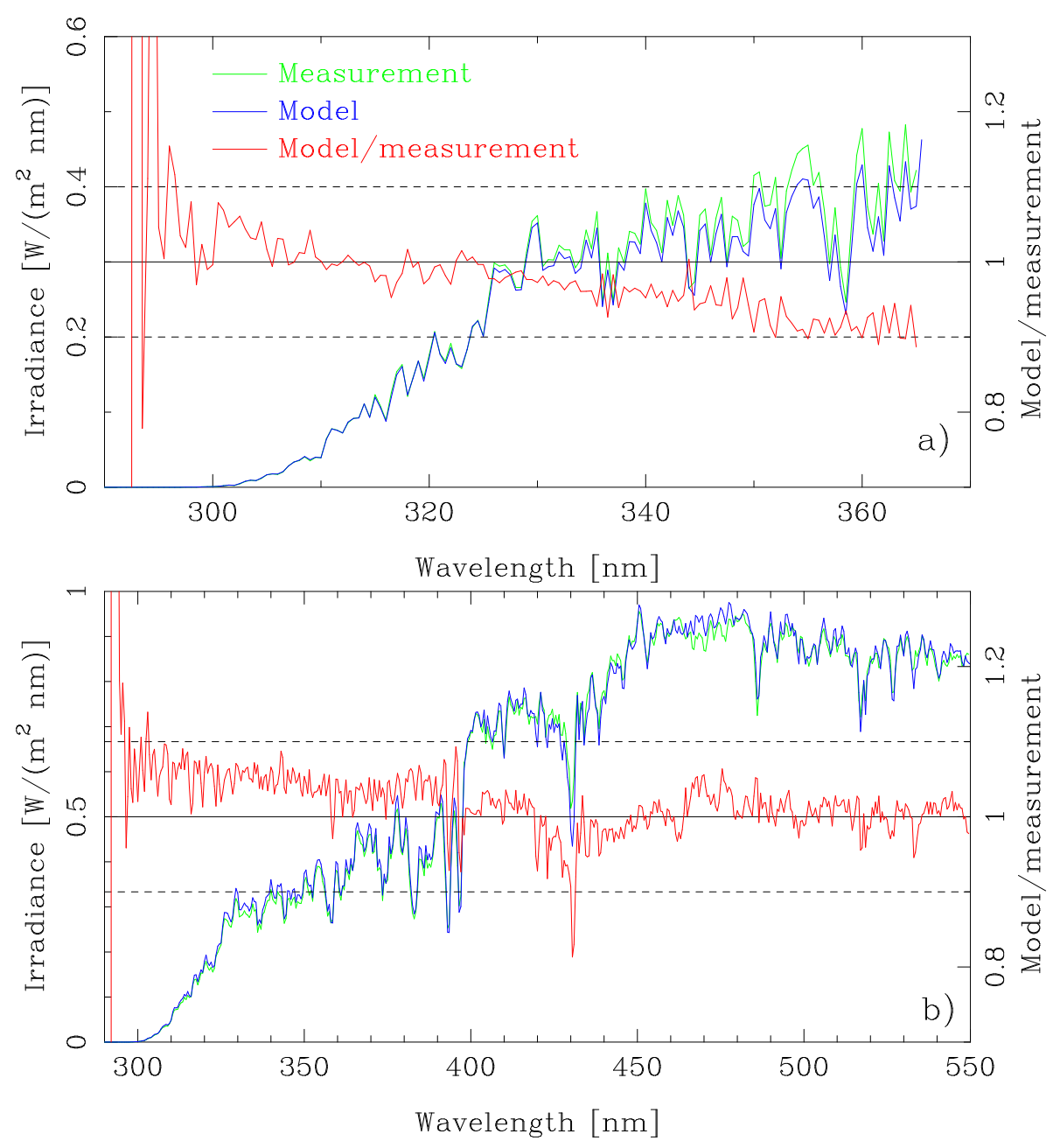

Fig. 1. Measured irradiance spectra, green lines, from the GRT instrument located at Briston, (a) and the NTN instrument at Aylsham, (b). The spectra were recorded at 14:00 UTC on day 255. In blue is shown the uvspec model simulations of the spectra. The red lines are the model/measurement ratios. Note the different scales on the $x$-axes in a) and b).

the descent and ascent around 12:00 UTC on day 257 and the ascent on day 263 are shown in Fig. 2. Using the water cloud parameterization of $\mathrm{Hu}$ and Stamnes (1993), the profiles on day 257 yield total cloud optical depths of about 30.3 for the descent and 19.7 for the ascent for a wavelength of $380 \mathrm{~nm}$. The cloud on day 263 was thinner, with an optical depth of about 9.2. The differences in the optical depths on day 257 are mainly caused by differences in $r_{e}$ between the ascent (dashed line) and the descent (solid line). For shortwave radiation, the water cloud volume extinction coefficient $\beta_{\text {ext }}$ is directly related to the liquid water content, $L W C$, and the droplet equivalent radius, $r_{e}$, (Stephens, 1978)

$$
\beta_{\mathrm{ext}} \approx \frac{3}{2} \frac{L W C}{r_{e}} .
$$

Thus, for a constant $L W C$, a reduction in $r_{e}$ by a factor of 2 will double the cloud optical depth. The in situ measured $r_{e}$ on day 263 is shown in Fig. 2 and varies over $4-9 \mu \mathrm{m}$ on day
257 and $3-6 \mu \mathrm{m}$ on day 263 . It is generally increasing with altitude. The sensitivity of the water cloud optical depth to $r_{e}$ may be exemplified by noting that for the ascent on day 257 the in situ optical depth was 19.7 at $380 \mathrm{~nm}$. Using the same $L W C$ but constant $r_{e}$ of $5,7.5$ and $10 \mu \mathrm{m}$ gives optical depths of 34.6, 22.7 and 16.9, respectively.

The effective cloud optical depths measured from the surface are shown in the Figs. 3b and 3d. For day 257, the cloud optical depths deduced from the NTN and GRT instruments were both around 38 at 1200. At 1140 the NTN optical depth was 32 . On day 263 the optical depths varied between 7 and 15 at the time the cloud profile was made (around 1300). These optical depths are larger than the optical depths derived from the in situ aircraft measurements. One possible reason for the discrepancy is cloud horizontal inhomogenity in the sense that the cloud optical depth was different at the locations of the aircraft and the ground stations. 

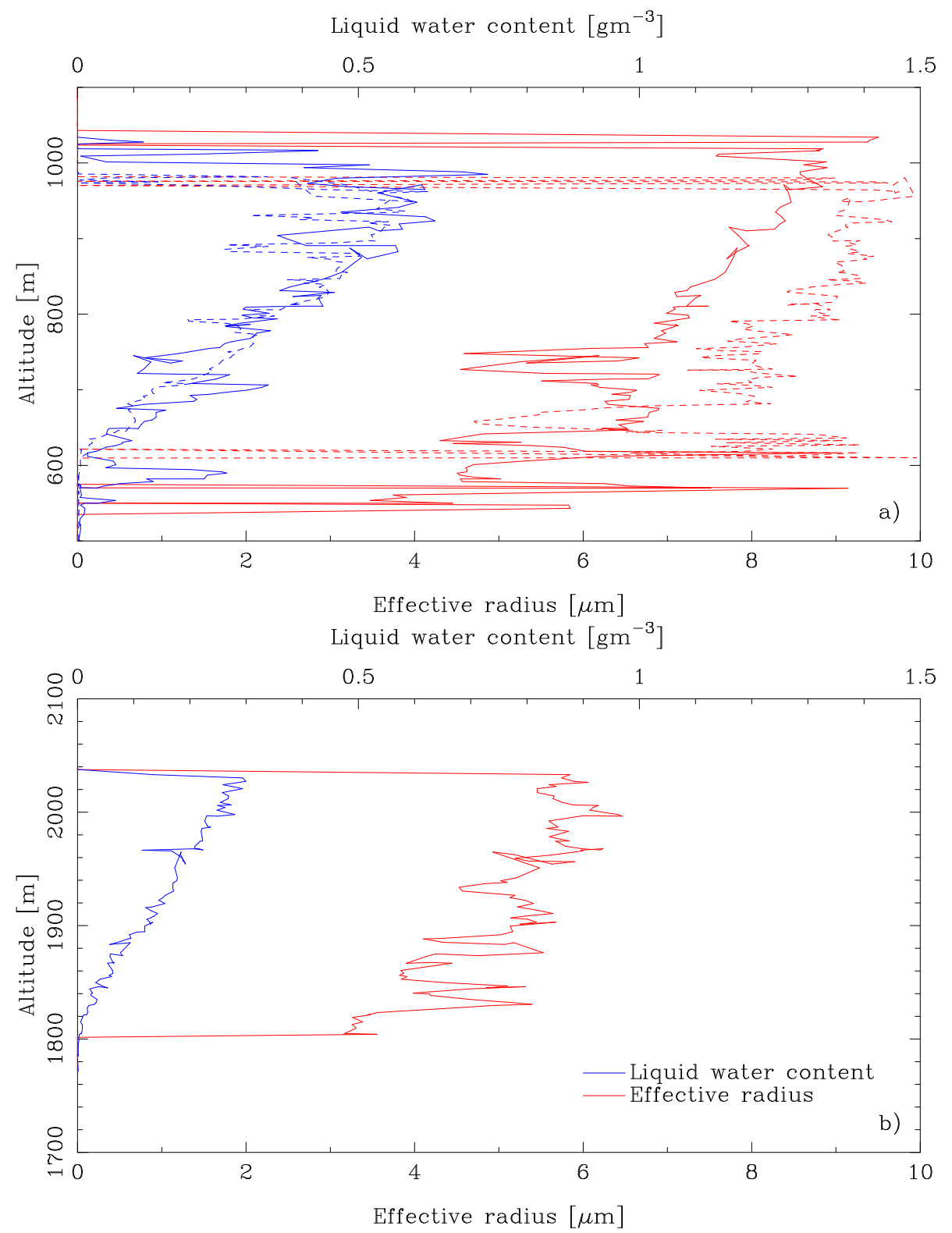

Fig. 2. Liquid water content (blue lines) as measured by the PVM instrument and the effective radius (red lines) measured by the Fast-FSSP instrument. In (a) the solid lines are from the descent and the dashed lines from the subsequent ascent on day 257 . In (b) the data are from day 263. Note different scales on the y-axes.

For day 257, the profile was made about $0.1^{\circ}$ south of the NTN site, and the wind was blowing from the north. On day 263, the profile was made slightly east of the Weybourne site. Thus, on both days cloud inhomogeneties may be part of the reason for the differences between the in situ and groundbased cloud optical depths. Just after the ascents on days 257 and 263, constant altitude legs were made above the clouds. The measured albedos derived from the Albedometer onboard the Partenavia, are shown in Fig. 4. The albedo appears to exhibit relatively small variations. However, the cloud optical depth of the underlying cloud may still vary considerably. In Fig. 5 is shown model simulations of the albedo as a function of cloud optical depth at the two flight altitudes. The clouds vertical distribution were taken from Fig. 2 and the total optical depth scaled between 0 and 50 . The solar zenith angles for the simulations were representative for the flight conditions. For day 257, the albedo varied between 0.65 and 0.75 . This corresponds to cloud optical depths between about 15 and 25. Similar numbers for day 263 are $0.4-0.5$ for the albedo and 2-6 for the cloud optical depth. Thus, horizontal variations of the cloud may explain the differences between the in situ aircraft and the 

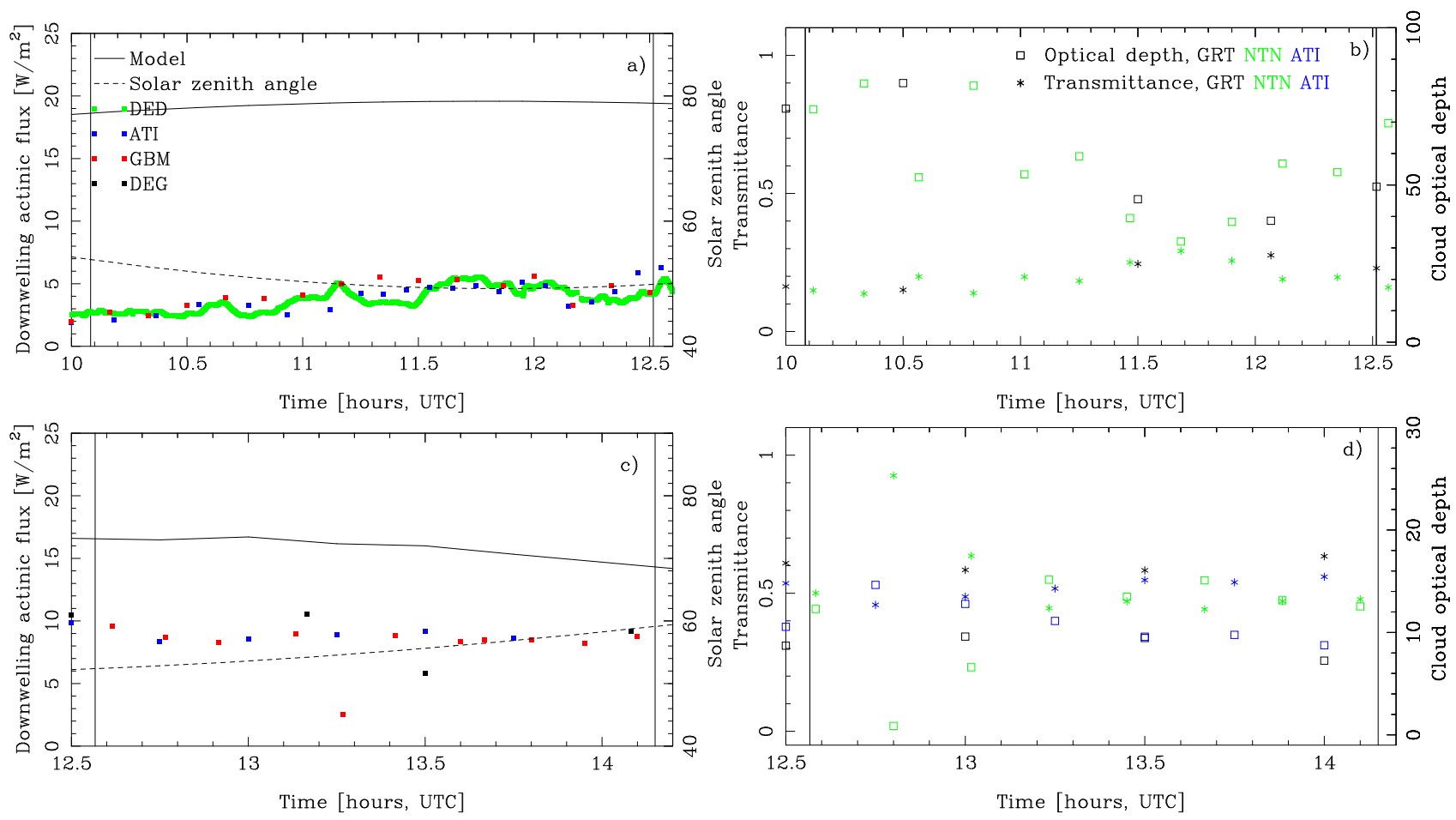

Fig. 3. Downwelling actinic fluxes integrated between 380-400 nm at the ground, (a) day 257 and (c) day 263, as measured in Weybourne (ATI, blue points), Beeston (GBM, red points), Briston (DEG, black points) and Aylsham (DED, green points). No data are available from the DED instrument on day 263. The black solid lines are cloudless model results for Weybourne, and the black dashed line is the solar zenith angle. In (b) and (d) are shown the effective cloud optical depths (squares) and the cloud transmittances (asterisks) for day 257, (b), and 263, (d). The black colours represent data from the GRT instrument, green the NTN instrument, and blue the ATI instrument. The black vertical lines indicate the interval in which the flights took place. Note different scales on y-axes of optical depth.

ground-based cloud optical depths. Nevertheless, the optical depths estimated from the ground measurements give a good indication of the horizontal variability over the domain and are used in the subsequent analysis.

\section{Measurements versus simulations}

Surface measurements were made continously in the period 12-29 September 2002. A number of flights were made during the same period. Here attention is paid to five days with clearly defined cloudless (1 day), overcast ( 2 days) and broken clouds periods ( 2 days) (Table 3 ).

\subsection{Cloudless situation}

At the very first day of the main campaign, 12.9, day 255, the sky was partly cloudy until about 12:00 UTC. It then cleared up and the sky became cloudless. Also, VELIS indicated that no subvisible cirrus was present. During the cloudless condition, flights were made over the ground stations in a triangular pattern. In addition, the ground stations intensified their measurement schedules.

\subsubsection{Ground data comparison}

The time evolution of the downwelling actinic flux is shown in Fig. 6. The downwelling actinic flux is shown for a wavelength region where ozone absorbs, 305-320 nm (Fig. 6a) and a wavelength region where ozone does not absorb, 380$400 \mathrm{~nm}$ (Fig. 6b). The different diurnal behaviour of the actinic flux in these two wavelength regions is evident. It is caused by the larger direct contribution to the total actinic flux at larger wavelengths. In addition to the measurements, simulations of the cloudless actinic flux are shown as well. The dip in the modelled clear-sky actinic flux between 1500 and 16:30 UTC is caused by significant increases, from about 0.05 to about 0.2 , in the aerosol optical depth. For the integrated $380-400 \mathrm{~nm}$ wavelength range, the DED measurements are about $2-4 \%$ smaller, while the ATI measurements are $4-6 \%$ higher than the simulations. The GBM measurements are $0-2 \%$ lower than the simulations for the same range. For the integrated $305-320 \mathrm{~nm}$ range, ATI and GBM are $3-10 \%$ higher than the model simulation, and DED is $3-10 \%$ lower. These spectral differences are also visible in individual spectra, as shown in Fig. 7 for the ATI and DED instruments, together with uvspec model simulations. The spectral resolution is higher for the spectrum from the ATI 

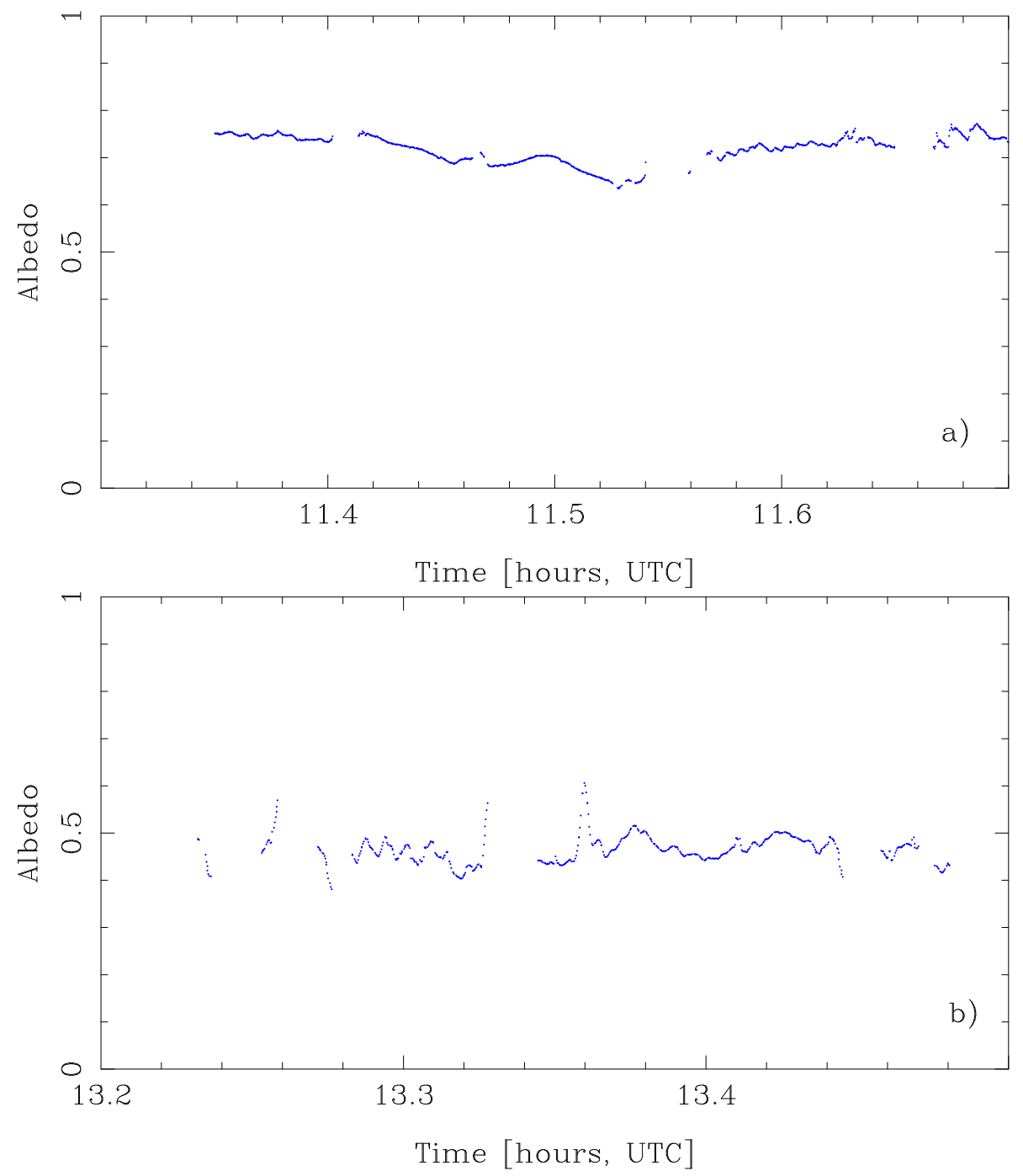

Fig. 4. Albedo for the 380-400 nm interval measured at constant flights altitudes of about $2830 \mathrm{~m}$, day 257 (a), and $2349 \mathrm{~m}$, day 263 (b). The albedo is derived from irradiance measurements onboard the Partenavia. Data points where the pitch of the aircraft was larger than $5^{\circ}$ or the roll was larger than $1^{\circ}$ have been excluded.

instrument. This is due to the spectral width of the slit function, which is 0.5 and $2.2 \mathrm{~nm}$ at FWHM for the ATI and DED instruments, respectively.

The measurement-model differences are of the same magnitude to those reported by Früh et al. (2003) for $2 \pi$ groundbased measurements of the actinic flux and to those reported by Hofzumahaus et al. (2002). In the latter, the $4 \pi$ spectral actinic flux measured between $120 \mathrm{~m}$ to $13000 \mathrm{~m}$ by an aircraft-mounted spectroradiometer was compared to the same radiative transfer model used here. Considering the uncertainties in both the measurements and the simulations, it is concluded that the simulations and the measurements agree within the uncertainties. Furthermore, the overall agreement between the measurements and the model simulations of the actinic flux is similar to that for the irradiances presented in Fig. 1.
The spectral actinic flux is about a factor 2 larger than the simultaneously measured irradiances shown in Fig. 1. This is in agreement with the theoretical predicitions for these solar zenith angles and atmospheric conditions of (e.g., Kylling et al., 2003b, in their Figs. 1 and 2 and Eq. 7). It is noted that no simple relationship exists between the irradiance and the actinic flux as such a relationship depends on various atmospheric parameters, all of which are generally not available (Ruggaber et al., 1993; Van Weele, Arellano and Kuik, 1995; Kylling et al., 2003b).

\subsubsection{Aircraft data comparison}

The flights made during the cloudless period went up to an altitude of about $2000 \mathrm{~m}$. The ascent starting at 13.6068 and ending at 13.8767 UTC was selected for further analysis. The 


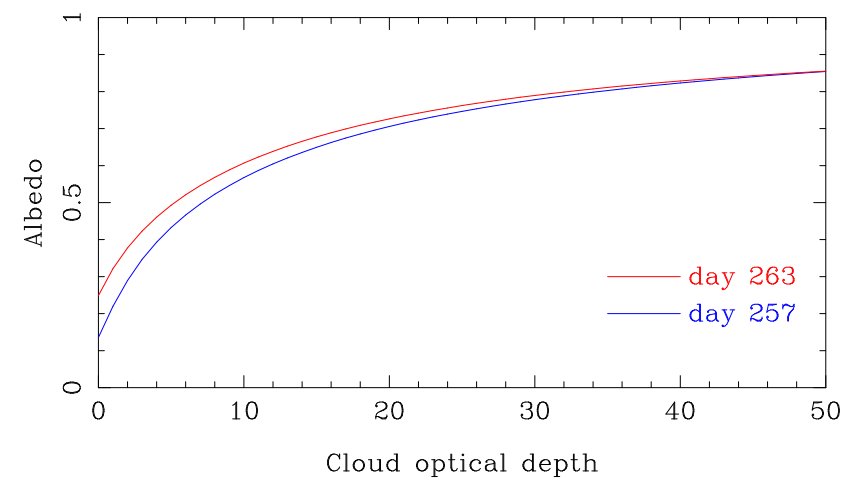

Fig. 5. Albedo as a function of cloud optical depth for days 257 (blue line) and 263 (red line). The albedo for day 257 (263) is calculated for a flight altitude of 2835 (2349) $\mathrm{m}$ and a solar zenith angle of $49.3^{\circ}\left(54.8^{\circ}\right)$.

solar zenith angle varied between $53.3^{\circ}$ and $54.8^{\circ}$ during the ascent. This variation in solar zenith angle caused less than $2 \%(6 \%)$ variations in the surface downwelling actinic flux in the UVA (UVB). This time slot is in the middle of the cloudless period, hence the data are minimally effected by possible clouds on the horizon.

In Fig. 8 is shown examples of the measured downwelling and upwelling actinic fluxes at some altitudes. Also shown are model simulations and model/measurement ratios. The downwelling measured and simulated actinic fluxes for all altitudes agree similarly to the measured and simulated irradiances shown in Fig. 1. The model overestimates by about $3-$ $4 \%$ below $320 \mathrm{~nm}$ and underestimates by $5-7 \%$ above about $350 \mathrm{~nm}$. This is within the combined model and measurement uncertainties. The latter is estimated to $\pm 8 \%$ in the UV range $(305-400 \mathrm{~nm})$ and $\pm 5 \%$ in the visible $(400-700 \mathrm{~nm})$ (Jäkel et al., 2005). For the upwelling spectra, the disagreement between the model and measurements is larger. For the $58 \mathrm{~m}$ altitude upwelling spectrum, the overall agreement is reasonable. Part of the structure seen may be caused by unaccounted wavelength shifts. All ground and aircraft spectra, except the upwelling aircraft spectra, have been wavelength shift corrected with the SHICRIVM algorithm (Slaper et al., 1995). The model overestimates the upwelling spectrum at $1961 \mathrm{~m}$ significantly below about $380 \mathrm{~nm}$. There is also a similar trend for the spectrum at $58 \mathrm{~m}$. Causes for the differences may be attributed to several reasons. One is the non-perfect angular response of the input optics. This gives crosstalk between the upper and lower hemisphere. For lowalbedo and low-altitude conditions, the contributions from the upper hemisphere to the lower hemisphere signal may be considerable (see Hofzumahaus et al., 2002, Fig. 6). The angular response correction depends on altitude, wavelength, surface albedo and solar zenith angle. In addition, clouds and aerosol will affect the correction. Angular correction factors as a function of wavelength, altitude, cloud, and surface albedo have been calculated using the discrete ordinate algorithm developed by Stamnes et al. (1988). A thorough discussion of the correction factors has been presented by Jäkel et al. (2005). The measurements have been corrected for the non-perfect angular response using these factors, however, an ideal correction implies complete knowledge about the sky radiance, which is not generally available. Also, the upwelling fluxes are rather sensitive to the albedo of the underlying surface. Uncertainties in the surface albedo estimate causes large changes in the upwelling radiation, especially for low altitudes and longer wavelengths. However, since the agreement was reasonable at $58 \mathrm{~m}$ and the albedo is small for the conditions here, the albedo is not a likely cause for the differences at $1961 \mathrm{~m}$. Furthermore, uncertainties in the aerosol optical depth, single-scattering albedo and asymmetry factor may affect the model results the most for the upwelling actinic flux at $1961 \mathrm{~m}$. The operational pitch and roll angles range of the stabilization system is $\pm 6^{\circ}$. During the ascent the acceleration of the aircraft meant that this range in periods was exceeded. Data outside the operational range was excluded from the analysis. Nevertheless, part of the ascent and descent data may be influenced by aircraft movements although the magnitude is assumed to be small. While the differences between the model and measurements are larger for the upwelling than the downwelling actinic flux, it is noted that the magnitude of the upwelling actinic flux is much smaller than the downwelling actinic flux for a cloudless sky and a small albedo. Hence, the contribution to the $4 \pi$ actinic flux is rather small from the upwelling part. Note that the FWHM of the DFD and DFU instruments is about $2.5 \mathrm{~nm}$. Hence, the spectra shown in Fig. 8 have similar spectral structure to those shown for the DED instrument in Fig. 7. In Fig. 9 vertical profiles are shown of the measured and simulated up- and downwelling actinic fluxes integrated over the $380-400 \mathrm{~nm}$ and $305-320 \mathrm{~nm}$ wavelength intervals. The differences between the measured and simulated actinic fluxes reflects the spectral differences discussed above and shown in Fig. 8. Both the down- and upwelling actinic fluxes increase with altitude for both wavelength intervals presented. The increase is largest for the upwelling actinic fluxes because as the altitude increase, the amount of atmosphere below the aircraft increase, thereby causing an increase of upscattered radiation due to Rayleigh scattering. The wavelength dependence of the Rayleigh scattering cross section also causes the increase in the upwelling actinic fluxes to be largest for short wavelengths. Similarily, the increase with altitude of the downwelling actinic flux is largest for the shortest wavelengths.

Except for the upwelling actinic flux, the model and the measurement agree within their uncertainties for the cloudless case. Furthermore, the measurements made at the different ground stations agree within their uncertainties. With this in the mind, attention is turned to overcast situations. 

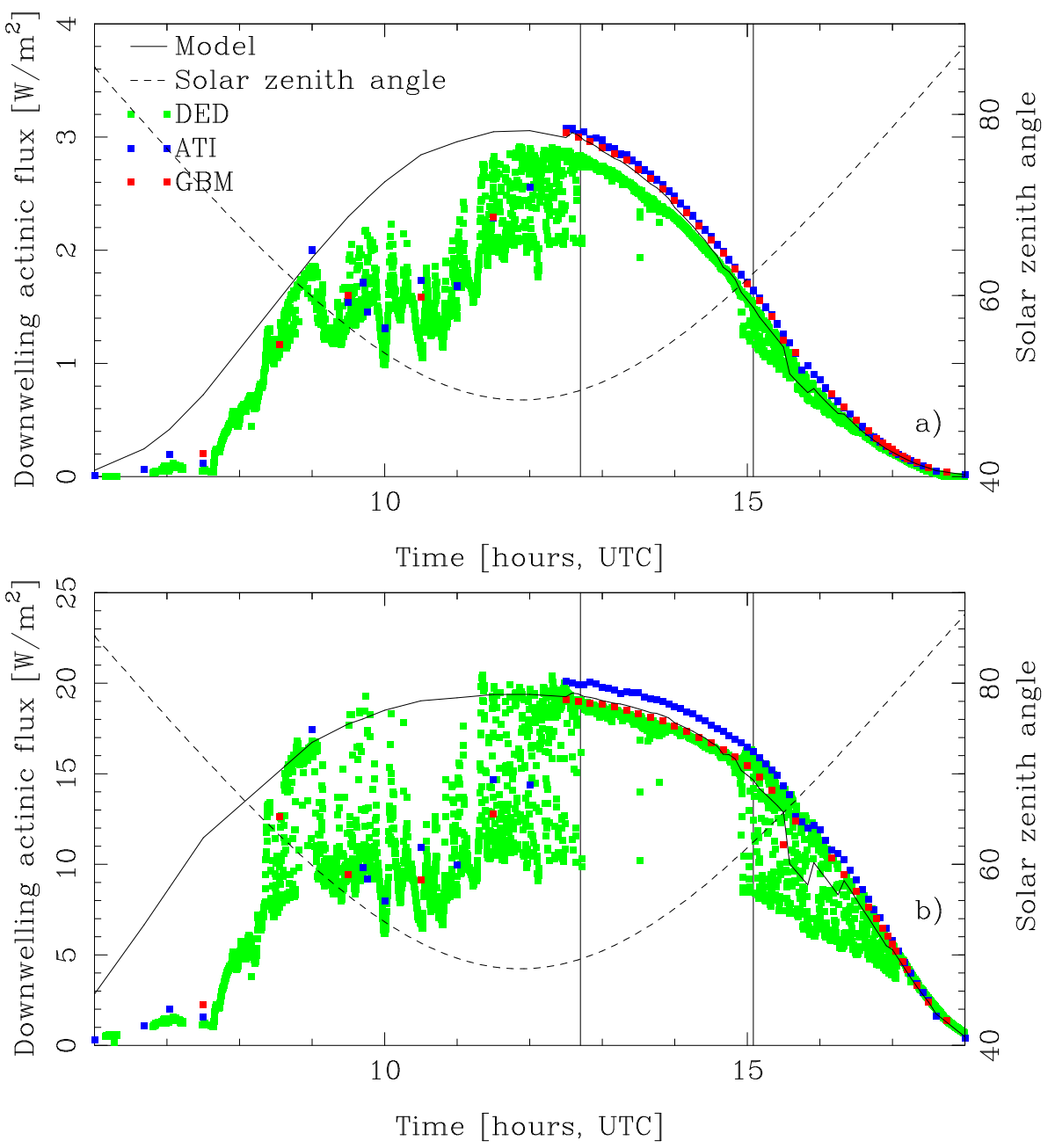

Fig. 6. Downwelling actinic fluxes at the ground as measured in Weybourne (ATI, blue points), Beeston (GBM, red points), and Aylsham (DED, green points), integrated between 305-320 (a) and 380-400 nm, (b). The black solid lines are cloudless model results for Weybourne. All data are from day 255. The black vertical lines indicate the interval in which the flights took place. The black dashed lines are the solar zenith angles.

\subsection{Overcast}

Two days, 14th and 20th of September (days 257 and 263), were considered as "homogeneous" overcast cases. In particular, 14 September was a "clean" situation with no cirrus above the stratocumulus cloud layer (Table 3).

\subsubsection{Ground data comparison}

In Fig. 3 the time evolution of the measured actinic flux on the ground is shown during the flights on these days. Also, the effective cloud optical depth as deduced from the surface irradiance measurements is shown. Compared to the cloudless situation, the actinic flux is reduced by about $75 \%(50 \%)$ on day 257 (263). The variability in the actinic flux during the flight hours indicates that the cloud was not horizontally homogeneous, and the downwelling actinic flux at times ex- hibited differences of about $40 \%$ between the stations. These variations are also seen in the cloud optical depth and transmittance in Figs. 3b and 3d. During the flight, the wind was from the north and relatively strong.

\subsubsection{Aircraft data comparison}

In Fig. 10 the measured and simulated actinic fluxes are shown as a function of altitude for the ascents (blue) and descent (red) on days 257 and 263. The black lines are model simulations of the measurements. The effect of the clouds on the actinic flux is similar on both days. Above the cloud the actinic flux is enhanced, a maximum is observed just below the cloud top in the downwelling actinic flux, and below the cloud the actinic flux is reduced compared to the cloudless situation. The variability seen at about $2900 \mathrm{~m}$ for the descent (red points) and $1500 \mathrm{~m}$ for the ascent (blue points) day 

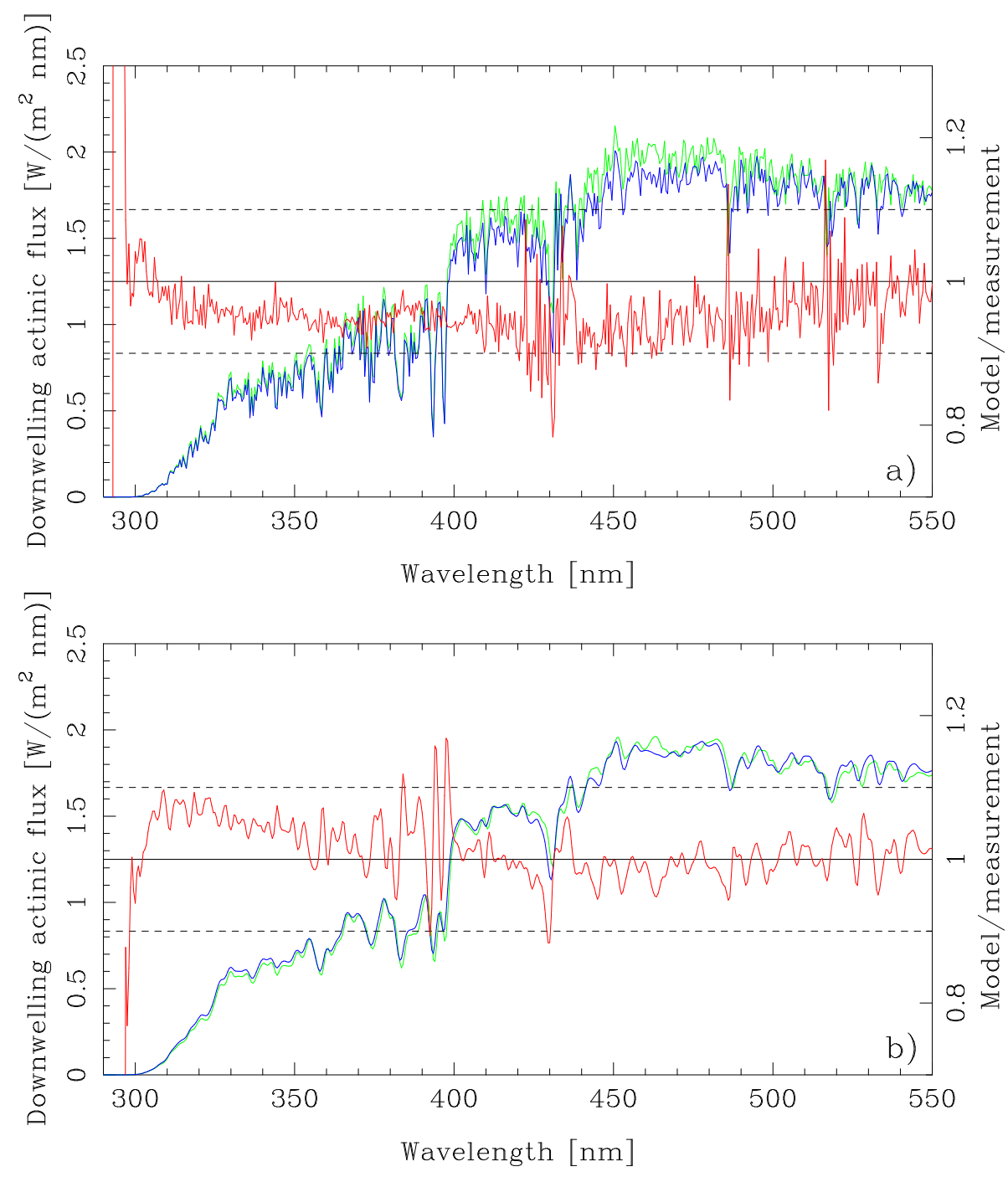

Fig. 7. Measured actinic flux spectrum (a), green line, from the ATI instrument located at Weybourne. The spectrum was recorded at 14:00 UTC on day 255. In blue is shown the uvspec model simulation of the spectrum. The red solid line is the model/measurement ratio. (b) Similar to (a) but for the DED instrument at Aylsham.

257, are due to the aircraft spending some time at these altitudes, thus viewing different parts of the clouds. These variations thus indicate cloud horizontal inhomogeneities and their effect of about $11 \%$ on the downwelling and total actinic fluxes for these measurements.

The above-cloud enhancement depends on the optical thickness of the cloud (see Fig. 9 of Van Weele and Duynkerke, 1993). The optical depth for the descent on day 257 was 30.3 and reduced to 19.7 for the ascent. A thicker cloud has a higher albedo, thus the above cloud actinic flux is higher for the descent, red points and dashed line in Fig. 10, compared to the ascent, blue points and solid line. Correspondingly, the optically thicker cloud transmits less radiation, resulting in lower below-cloud radiation than the optically thinner cloud.
Just below the cloud top, theory predicts a maximum in the actinic flux. The maximum has theoretically been described by Madronich (1987) and Van Weele and Duynkerke (1993). The magnitude of the maximum is largest for small solar zenith angles and decreases as the solar zenith angles increases (de Roode et al., 2001, and Fig. 11). Also, the magnitude of the maximum increases with increasing cloud optical depth, while the geometric extent decreases with increasing cloud optical depth. The effect disappears for large solar zenith angles. The maximum occurs at optical depths were the direct beam is still significant and the diffuse radiation is becoming appreciable. It is noted that for the solar zenith angles encountered during days 257 and 263 (Table 3), the calculations shown in Fig. 11 indicate that the maximum might be seen in the downwelling actinic flux measurement. 

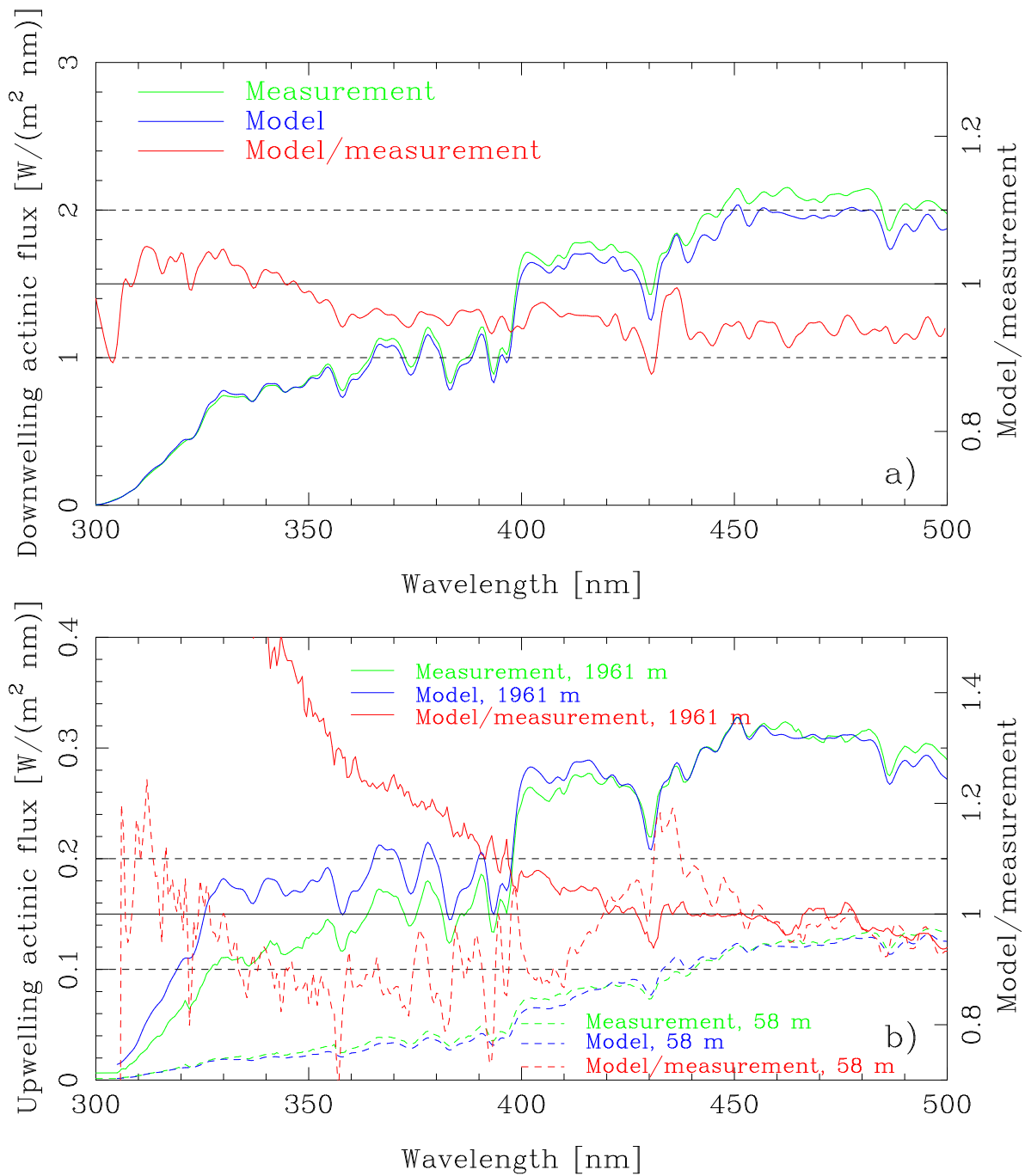

Fig. 8. Downwelling actinic flux (a) (green line) at an altitude of $1961 \mathrm{~m}$ as measured by the DFD spectroradiometer on day 255 at $1353(\mathrm{hhmm})$ and $12.9 \mathrm{~s}$. (b) The upwelling actinic flux (green line) measured by the DFU spectroradiometer on day 255 at an altitude of $1961 \mathrm{~m}$, dashed lines, (58 m, solid lines) at 1350 and $44 \mathrm{~s}$ (1336 and 4.9s). Model simulations are shown as blue lines and the model/measurements ratios are shown in red.
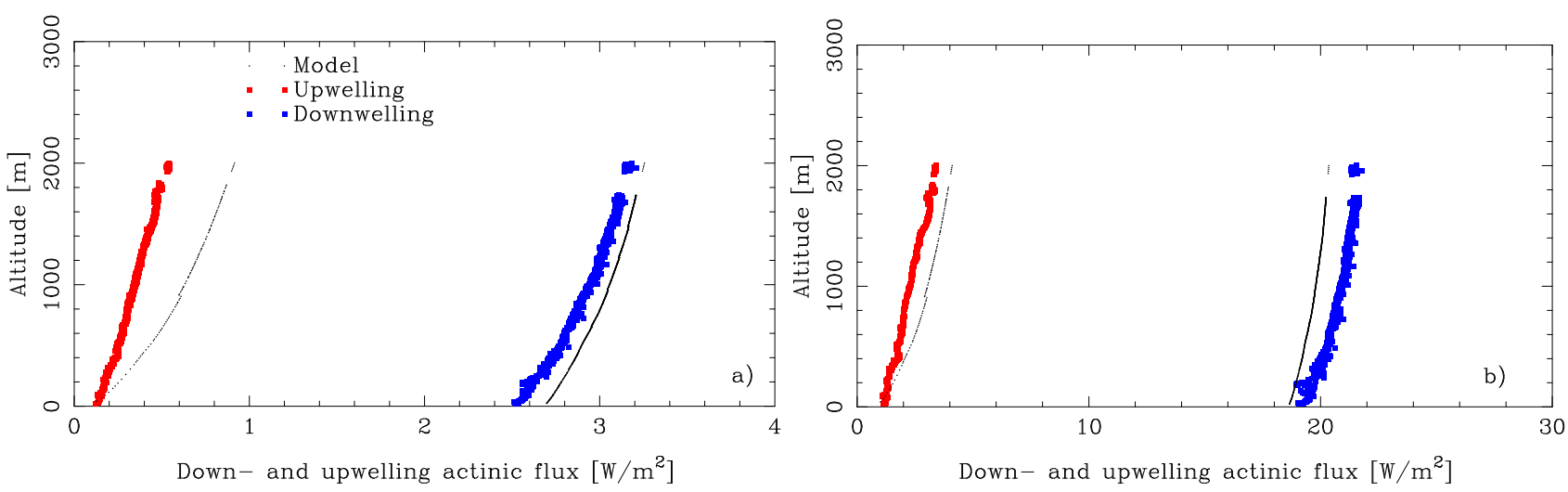

Fig. 9. Downwelling (blue points) and upwelling (red points) actinic fluxes as a function of altitude integrated between 305-320 nm (a) and 380-400 nm (b). The black solid lines are model simulations. 

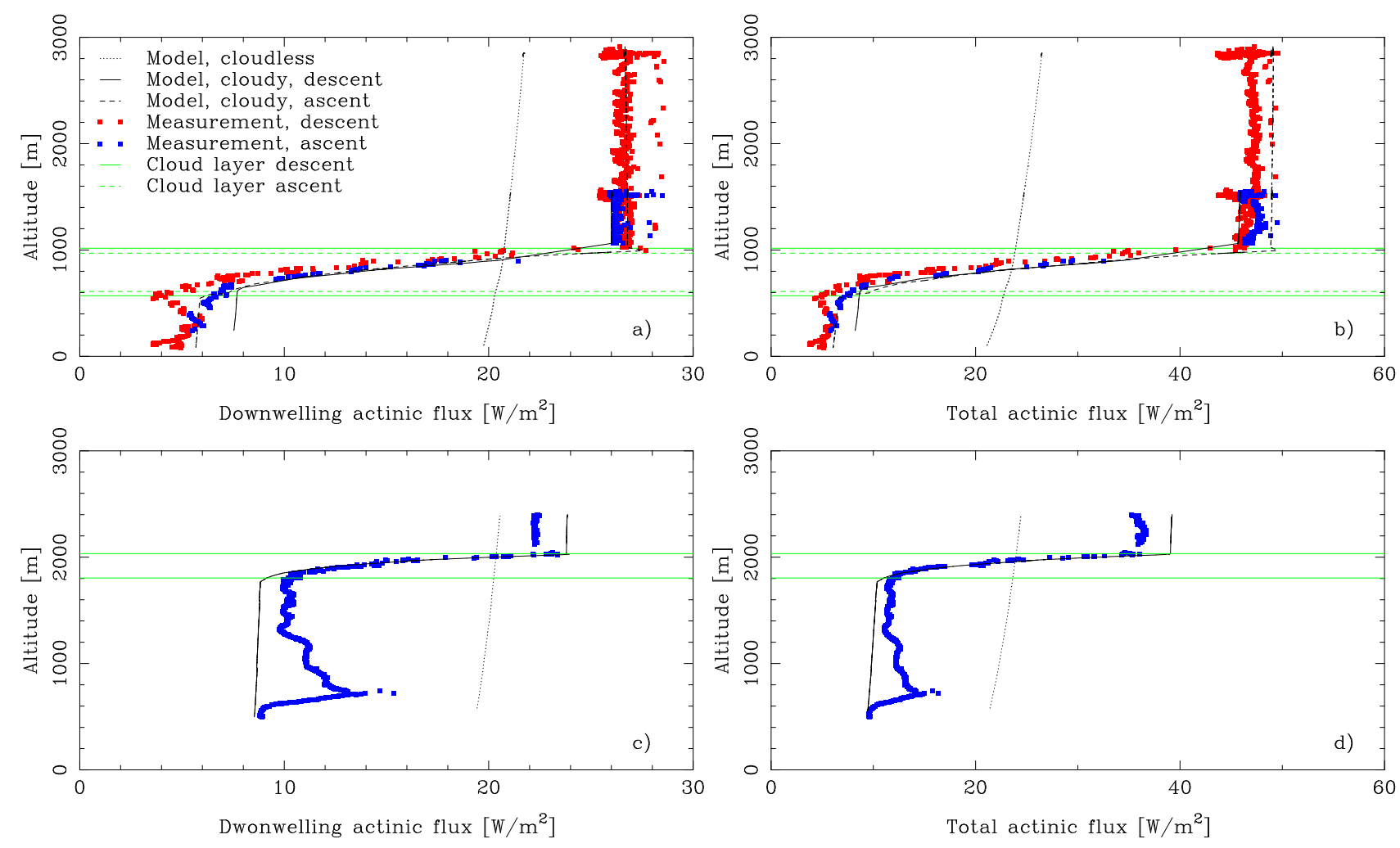

Fig. 10. Measured downwelling, (a) and (c), and total, (b) and (d) (downwelling plus upwelling) actinic fluxes integrated between 380$400 \mathrm{~nm}$ as a function of altitude for days 257 (a) and (b), and 263, (c) and (d). The blue points are from the ascents and the red points from the descent. Descent data for day 263 are not available as the descent was made outside the grid box under investigation. The dashed and solid lines represent simulations of the ascent and descents respectively. The dotted black lines are cloudless model calculations and the horizontal green lines indicate the top and bottom of the cloud layers.

Inspection of the measurements and the model simulations of the downwelling actinic flux, Fig. 10a and c, reveals a maximum for both days. It is noted that for the ascent on day 257 , the maximum is not observed. This may be due to the lack of data in the topmost part of the cloud or cloud top inhomogeneties. No enhancement is seen in the total actinic flux. This is in agreement with the model predictions shown in Fig. 11 where a maximum is observed in the downwelling actinic flux for a solar zenith angle of $40^{\circ}$, but not in the total actinic flux. Similar enhancements around cloud top have been observed in tethered-balloon measurements by de Roode et al. (2001) and Vilà-Guerau de Arellano et al. (1994). Below the maximum the actinic flux decreases monotonically with decreasing altitude until cloud bottom. Below the cloud the actinic flux varies little with altitude. This is typically for the effect of clouds over surfaces with a low albedo. Over high-albedo surfaces such as snow, the behaviour is significantly different (de Roode et al., 2001).

The overall agreement in Fig. 10 between the model simulations and the measurements is good. The simulations capture the main features of the measurements. However, some differences are evident, especially below the cloud bottom where the model is consistently larger than the measurements for day 257 and smaller then the measurements for day 263. As shown in Fig. 4, the clouds were not homogeneous, which clearly affected the radiation measurements. The relative differences in the transmittance between the stations were larger on day 263 compared to day 257 (see Fig. 3). This further indicates cloud horizontal inhomogeneities, which may explain the larger below-cloud differences for day 263 compared to day 257. The model simulations are 1-D and hence do not account for any horizontal variability.

Compared to a cloudless atmosphere, the cloud on day 257 increases the downwelling actinic flux by about $30 \%$ above the cloud and reduces it by about $65 \%$ below. Similar numbers for the total actinic flux are about $100 \%$ and $55 \%$, respectively. The cloud on day 263 is thinner, hence more radiation penetrates the cloud and less is scattered back. The total (downwelling) flux is increased by about $60 \%(20 \%)$ above the cloud and reduced by about 55\% (55\%) below the cloud. These number for the total actinic flux are in agreement with those reported by e.g. Vilà-Guerau de Arellano et al. (1994) and Shetter and Müller (1999). 

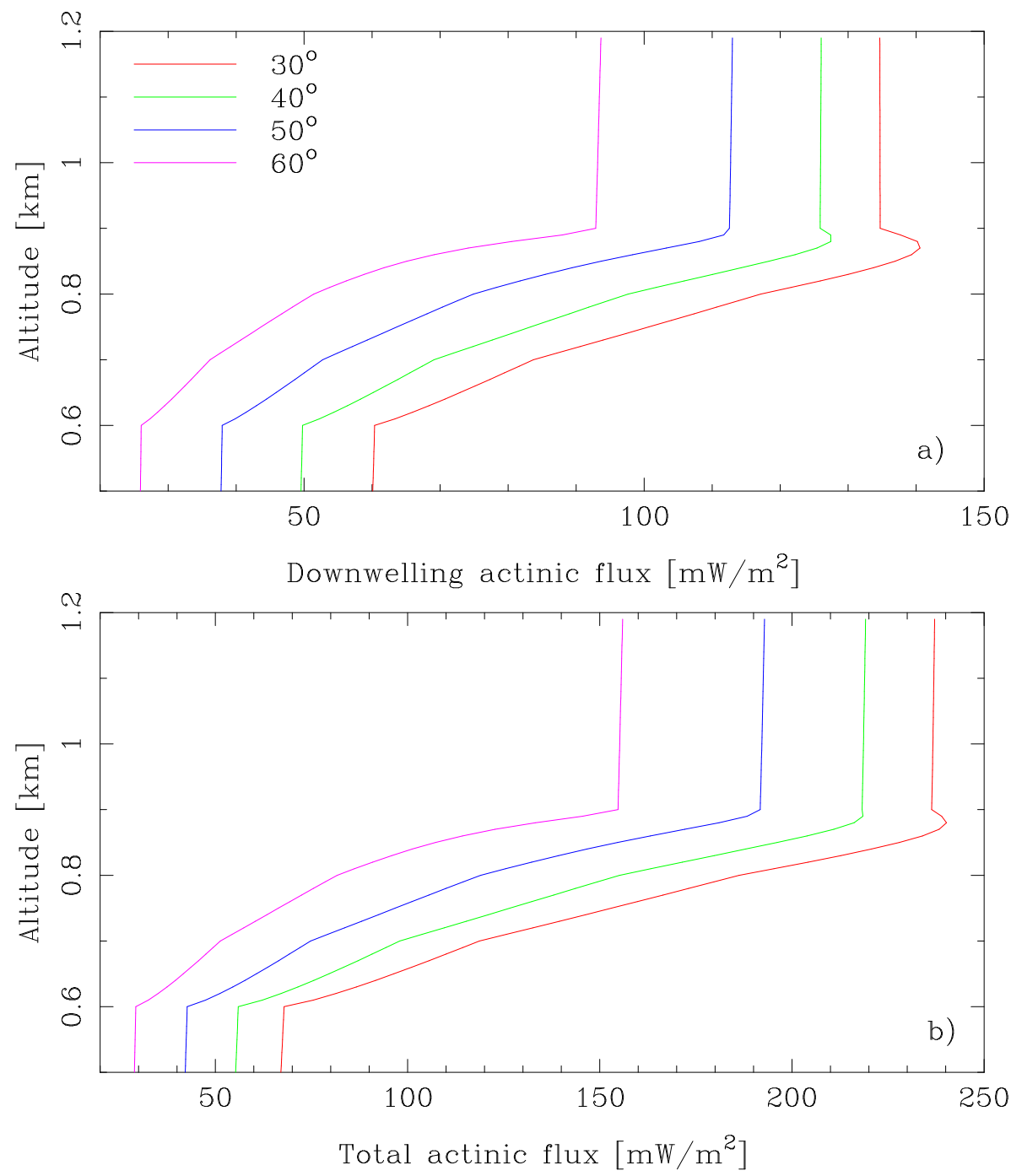

Fig. 11. Modelled downwelling, (a), and total (downwelling plus upwelling), (b), actinic fluxes for $360 \mathrm{~nm}$ as a function of altitude for various solar zenith angles.

\subsection{Broken clouds}

The above discussed cases may be considered "simple" 1-D upon visual inspection although closer analysis reveal possible 3-D effects. More complex cases include broken clouds, multi-layer clouds and combinations of these. On day 256, "cloud bands" oriented west-east covered 4 oktas (4/8) over land. A snapshot of the cloud bands is provided in Fig. 12. There was no cirrus on that day. Day 261 was a rather complex situation with quite inhomogeneous cumulus/stratus between 500 and $1900 \mathrm{~m}$ and $4 / 8$ to $8 / 8$ cirrus between 11 and $14 \mathrm{~km}$. The cloud inhomogeneity was clearly visible from below (see Fig. 12). Two flights were made on day 256. Data from the second and longest flight are analysed here together with data from the flight on day 261.

\subsubsection{Ground data comparison}

In Fig. 13 the downwelling actinic flux measured on the ground on these two days during the flights is shown. Also shown are the effective cloud optical depths and transmittances as deduced from the ground measurements. On day 256 , the cloud bands were only present inland. This is seen in Fig. 13, as the measurements by the ATI and GBM instruments on the coast are representative of cloudless conditions. The inland measurements by the DED instrument vary rapidly as the cloud bands pass over the measurement site. Occassionally the measurements are larger than the cloudless model simulations, shown as a solid black line. This indicates the combined effect of scattering off cloud sides and a visible solar disk (Mims and Frederick, 1994; Nack and Green, 1974). The variations seen in the actinic flux of the DED instrument are also evident in the transmittance and 

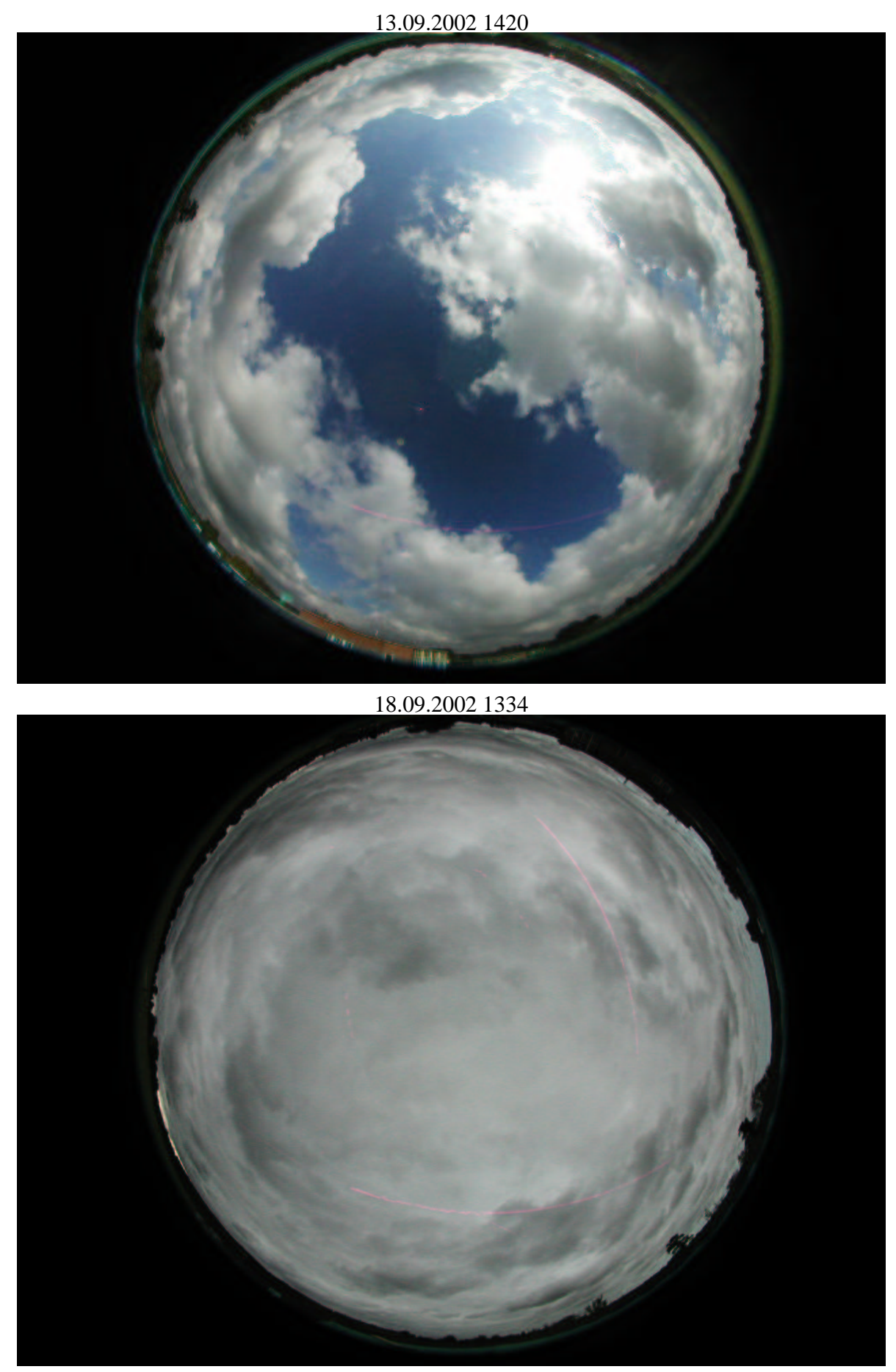

Fig. 12. All-sky pictures taken at Briston on day 256 at 1420 (top) and day 261 at 1334 (bottom).

cloud optical depths deduced from the inland GRT and NTN instruments. Note, however, that the time resolution of these instruments are lower than for the DED instrument. Both episodes of cloud gaps and cloud bands are readily identified in Fig. 13. The steps in the cloudless model results, black solid lines, are due to changes in the aerosol optical depth deduced from VELIS.
On the ground fewer variations are seen at the individual stations on day 261 (see Fig. 13). However, the variations between the stations are of the same magnitude as the variations at Aylsham, DED, on day 256. Thus, while the sky appeared to be more homogeneous on day 261 compared to day 256, Fig. 12, the cloud inhomogeneties caused considerable variations over the area covered by the ground stations. This 

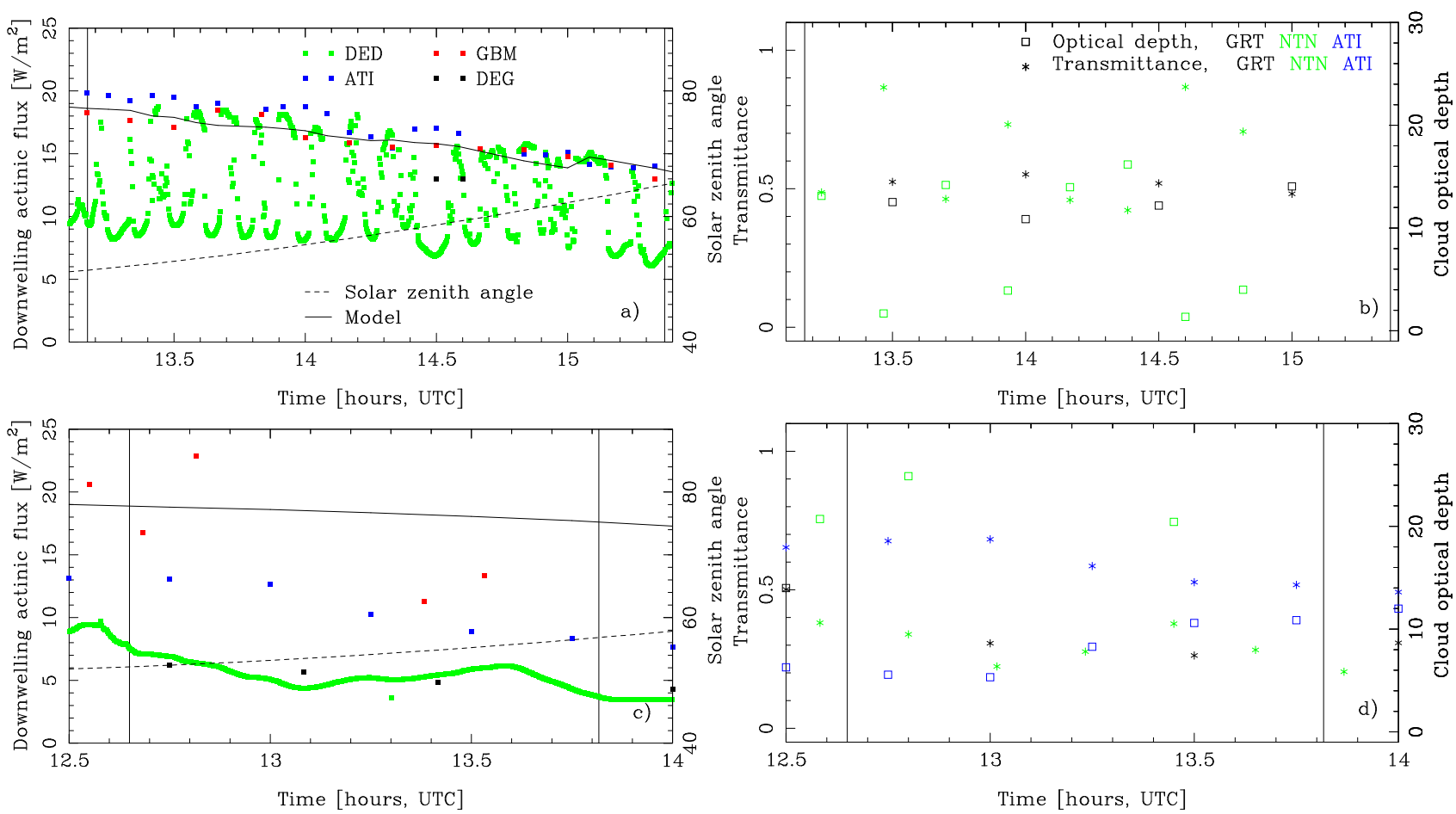

Fig. 13. Downwelling actinic fluxes, (a) and (c) at the ground as measured in Weybourne (ATI, blue points), Beeston (GBM, red points), Briston (DEG, black points) and Aylsham (DED, green points). The black solid lines are cloudless model results for Weybourne and the black dashed lines are the solar zenith angles. The effective cloud optical depth (squares) and the cloud transmittance (asterisks) are shown for days 256 (b) and 261, (d). The black colour represents data from the GRT instrument, green the NTN instrument, and blue the ATI instrument. The black vertical lines indicate the interval in which the flights took place.

is also evident in the albedo measurements shown in Fig. 14. Most of time the aircraft is above the clouds. The parts within the clouds are readily identified by large and spurious variations in the albedo. These are during the ascents and descents at the beginning and end of both flights and around 1400 for the flight on day 256. For both days, the large variations in the albedo measured while the aircraft was above the clouds reflect the horizontal inhomogeneties of the clouds. For day 256 , the minimum albedo is close to the cloudless albedo, while the maximum albedo reflects that the clouds were not optically thick on this day. On the other hand, the clouds on day 261 were thicker, with smaller and fewer gaps, thus producing the higher minimum and maximum albedos.

\subsubsection{Aircraft data comparison}

In order to simulate the measurements, vertical profiles of the liquid water content and effective droplet radius are required. As the clouds were inhomogeneous, it was not possible to select data from a single cloud penetration as done above for days 257 and 263. Instead, all liquid water content data from the PVM and all effective radius data from the FastFSSP were plotted as a function of altitude, Fig. 15. For the cloud band, day 256, it was assumed that the cloud was vertically homogeneous with a liquid water content of $0.5 \mathrm{gm}^{3}$ and $r_{e}=5.5 \mu \mathrm{m}$. Cloud bottom was at $900 \mathrm{~m}$ and cloud top at $930 \mathrm{~m}$. With the Hu and Stamnes (1993) parameterization, this resulted in a cloud optical depth of 4.3 at $380 \mathrm{~nm}$. The optical depths derived from the ground measurements varied between 10 and 16 when clouds were overhead, Fig. 13 . As discussed earlier, this difference may be caused by cloud horizontal inhomogeneties.

For day 261 the clouds had a larger vertical extent. A near-adiabatic liquid water profile was assumed and values between the maximum and minimum measured liquid water contents adopted. The $r_{e}$ was assumed to increase with altitude, Fig. 15. This resulted in an optical depth of 31.7 at $380 \mathrm{~nm}$. The inland, ground-deduced optical depths varied between 20 and 25, which, again considering horizontal variations, is consistent with the cloud built from the PVM and Fast-FSSP measurements.

In Fig. 16, the total and downwelling actinic fluxes measured by the Partenavia on days 256 and 261 are shown as a function of altitude. Also shown are model simulations for cloudless and cloudy conditions. For the cloudy simulations, the cloud properties shown in Fig. 15 were used. As mentioned earlier, day 256 was characterised by cloud bands oriented west-east. Thus, from the ground, it was either cloudy or the sun could be seen. The flight on day 256 

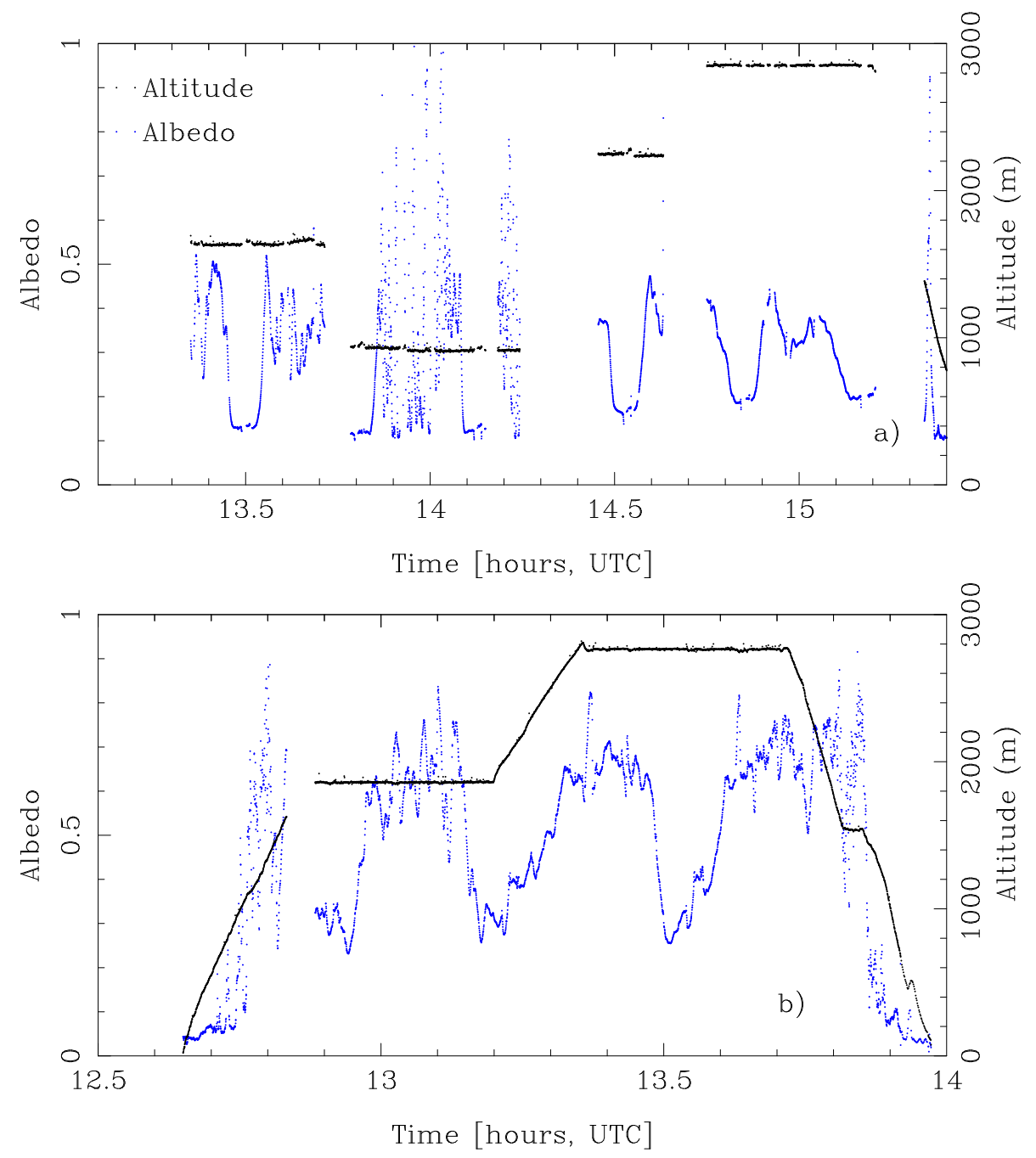

Fig. 14. Albedo at $380 \mathrm{~nm}$ measured during the flights on day 256, (a), and day 261, (b). The albedo is derived from irradiance measurements onboard the Partenavia. The black solid lines show the altitude of the aircraft. Data points where the pitch of the aircraft was larger than $5^{\circ}$ or the roll was larger than $1^{\circ}$ have been excluded.

lasted for about $2.5 \mathrm{~h}$. During this time period the solar zenith angle increased from about $52^{\circ}$ to $65^{\circ}$. This changed the actinic fluxes by about $30 \%$ below the cloud and about $25 \%$ for the cloudless conditions. The variability seen in the actinic fluxes of about $\pm 10 \%$ when the aircraft was at constant altitude above the clouds, reflects the changes in the cloud cover underneath. See, for example, the horizontally oriented data points at about 1600, 2300 and $2800 \mathrm{~m}$ in Fig. 16a and b. The ground measurements on day 256 of the downwelling actinic flux varies between 6 and $19 \mathrm{~W} / \mathrm{m}^{2}$, Fig. 13. This is in agreement with the below-cloud aircraft measurements (see Fig. 16). Above the cloud, the aircraft measurements are $0-150 \%$ larger than the cloudless ground measurements.

For day 261, the picture is more complicated due to the horizontal and vertical variations of the cloud cover. The cloud simulations obviously have the cloud bottom placed a little too high. The ground measurements varied between 3 and $16 \mathrm{~W} / \mathrm{m}^{2}$ (see Fig. 13). The same variability is not seen in the aircraft data. However, this is caused by the fact that only one ascent and descent was made on that day. Thus, the aircraft data may not be fully representative for the whole area in its full vertical and horizontal extent.

As can be seen in Fig. 16, the measurements lie between the cloudless, $F_{\text {clear }}$, and cloudy, $F_{\text {cloudy }}$, 1-D model simulations. Thus, for this situation a simple cloud fraction, $C_{f}$, approximation

$F=C_{f} F_{\text {cloudy }}+\left(1-C_{f}\right) F_{\text {clear }}$

might yield representative values for the total actinic flux, $F$, provided that the vertical extent of the cloud and its optical properties were known, and that a realistic value of $C_{f}$ is available. For day 256, values of 0.3 (green), 0.5 (red) and 

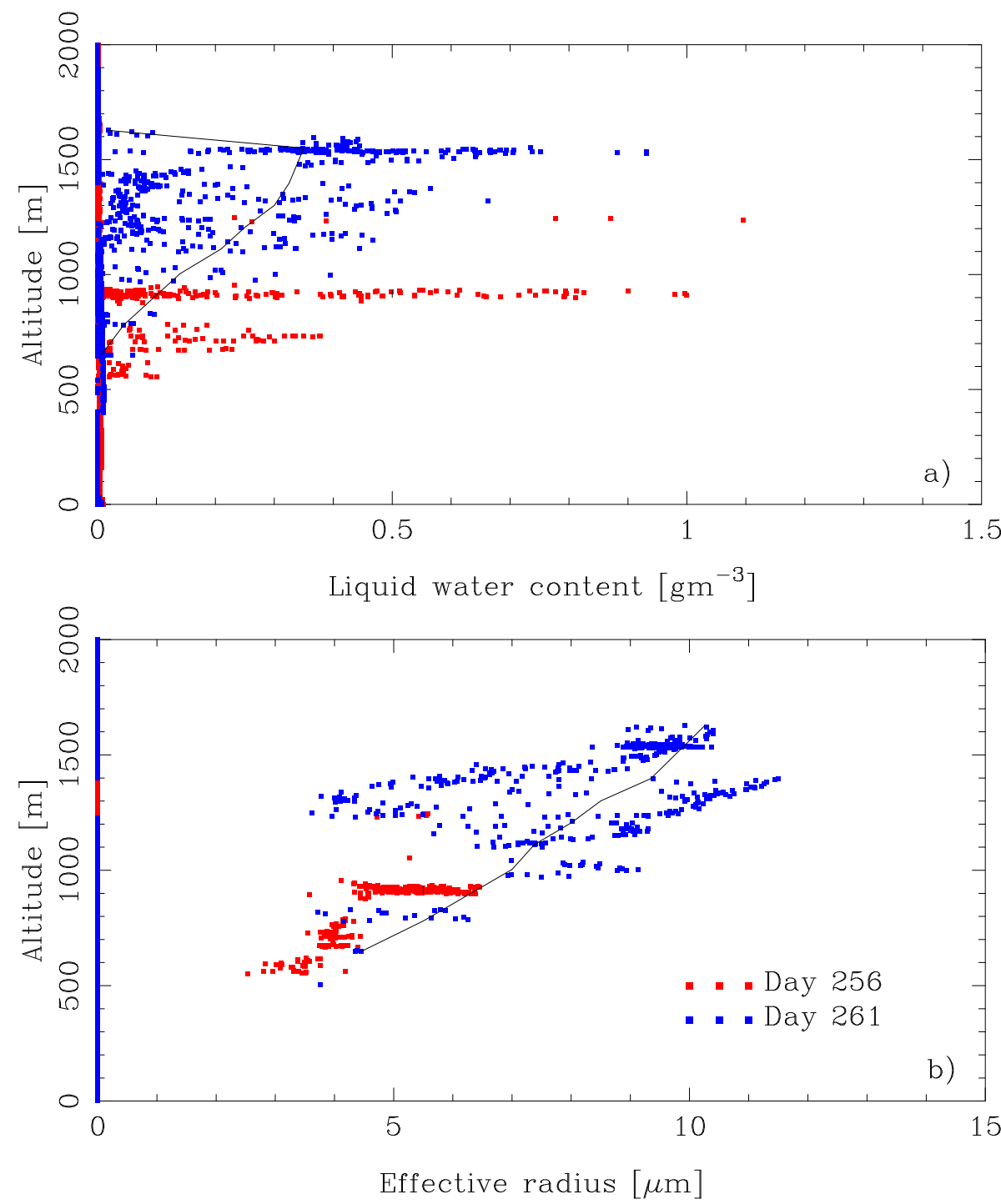

Fig. 15. Liquid water content, (a), as measured by the PVM instrument and the effective radius, (b), measured by the Fast-FSSP instrument. Red dots are data from day 256 and blue dots data from day 261. The solid lines are the input used for the model simulations.

0.7 (blue) were used for $C_{f}$. The above cloud actinic flux is reasonably well captured by any of these cloud fractions. However, below the cloud the actinic flux is either represented by cloudless or overcast calculations. Thus the cloud fraction approximation appears to only capture part of the picture for this situation. For day 261, values of 0.5 (green), 0.6 (red) and 0.7 (blue) were used for $C_{f}$. The overall best agreement both above and below the cloud is obtained with a value of 0.6 , although the below-cloud actinic flux is slightly overestimated. The best agreement below the cloud is obtained for $C_{f}=0.8$ (not shown). However a value of 0.8 overestimates the actinic flux above the cloud. Thus, the cloud fraction approach appears to be too simple to describe both the above-cloud enhancement and the below-cloud reduction by a single number. It must also be noted that during such inhomogeneous and changing conditions, it is not feasible to sample a larger area with aircraft. Thus, the measured data may not be fully representative for the area under investigation.

Based on the images shown in Fig. 12, the cloud amounts are estimated to 4 oktas on day 256 and between 7 and 8 oktas for day 261. The relationship between cloud amount as estimated by a surface observer and the earthview (vertical) cloud amount needed in radiative transfer models has been discussed by Henderson-Sellers and McGuffie (1990) and references therein. For mid-range cloud amounts, the two views are comparable. This agrees with the findings here that a $C_{f}=0.5$ gives a reasonable representation above the cloud for day 256. For large cloud amounts, surface observations tend to overestimate cloud amount as compared to the 

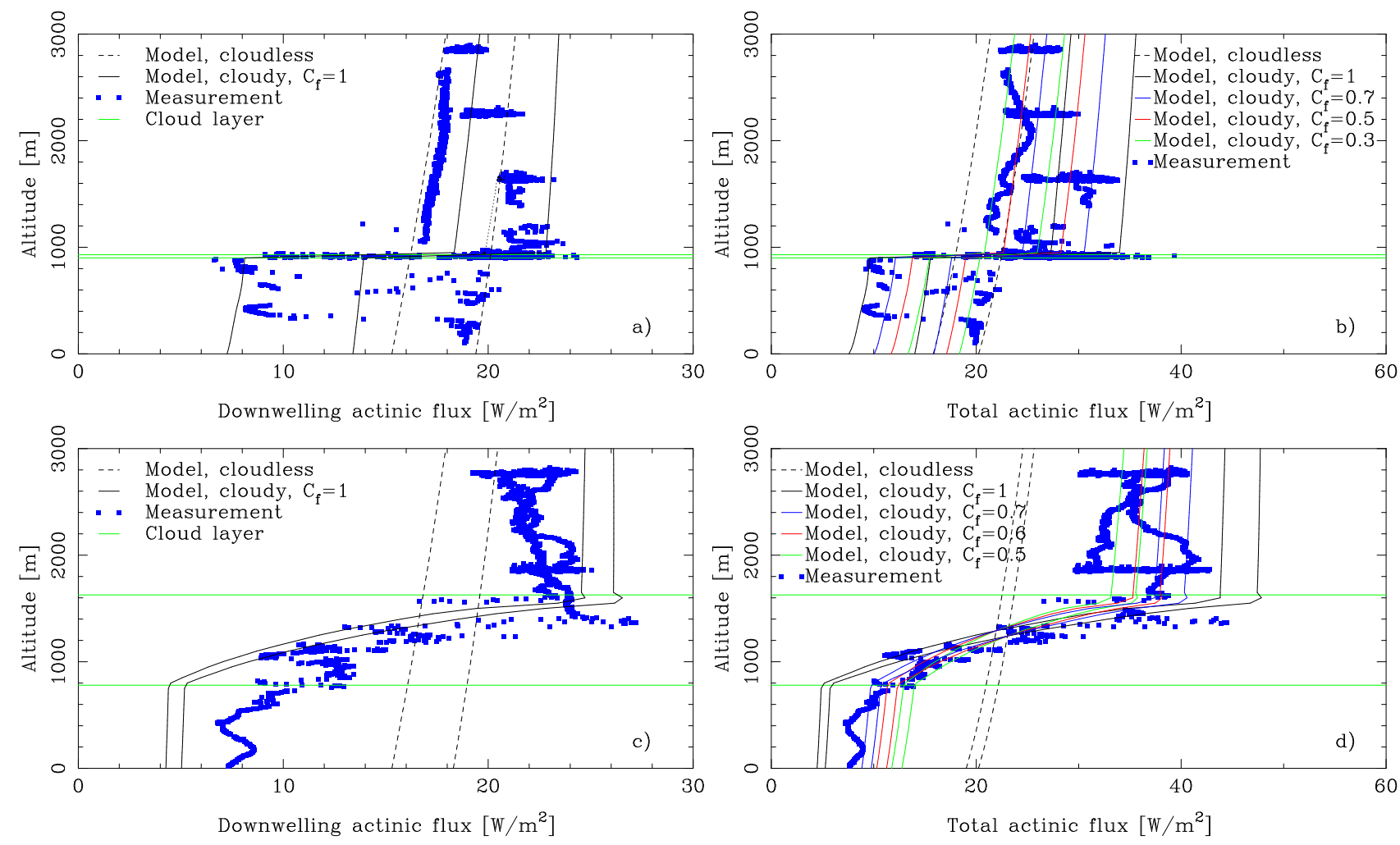

Fig. 16. Downwelling, (a) and (c), and total, (b) and (d), actinic fluxes integrated between 380-400 nm for the entire flights on day 256, (a) and (b), and day 261, (c) and (d), as a function of altitude. The solid lines are model simulations including the model clouds from Fig. 15 with different cloud fractions. For day 256, black is $C_{f}=1.0$; green $C_{f}=0.3$; red $C_{f}=0.5$, and blue $C_{f}=0.7$. Similarily for day 261, black is $C_{f}=1.0$; green $C_{f}=0.5$; red $C_{f}=0.6$, and blue $C_{f}=0.7$. The dashed lines are cloudless model simulations. For all lines, the rightmost (leftmost) lines are for the smallest (largest) solar zenith angles encountered during the flights, see Fig. 13. The horizontal green lines indicate the top and bottom of the cloud layers.

earthview cloud amount. This is also found here, as a value of $C_{f}=0.9$, or about 7 oktas, overestimates the actinic flux by about $16 \%$ above the cloud and underestimates the actinic flux by about $33 \%$ below the cloud, compared to $C_{f}=0.6$. Thus, while all-sky images are useful to document the measurement conditions and in the selection of interesting cases, direct use of cloud amounts deduced from these images must be used with care in models.

\section{Conclusions}

As part of the INSPECTRO project, an extensive campaign to study the influence of clouds on the spectral actinic flux in the lower troposphere was carried out in East Anglia, England, September 2002. The spectral actinic flux, the irradiance and aerosol and cloud properties were measured by aircraft and four ground stations.

Data from cloudless, broken cloud and overcast situations were selected for analysis. A detailed radiative transfer model was used to simulate and interpret the measurements. The following findings were made.
- For cloudless conditions, the measurements of the total and downwelling actinic flux were reproduced by the radiative transfer model within the measurement and model uncertainties of about $\pm 10 \%$.

- Under cloudless conditions the upwelling actinic flux contributed between 5 to $30 \%$ to the total actinic flux depending on wavelength and altitude. Above $300 \mathrm{~nm}$ the measured and simulated downwelling actinic fluxes agreed within $\pm 10 \%$. For shorter wavelengths the differences were larger.

- For cloud conditions visually characterised as horizontally homogeneous, the downwelling actinic flux at the surface at times varied by up to $40 \%$ between stations for the rather small experimental area of about $12 \times 12 \mathrm{~km}^{2}$. Simultaneously, the above-cloud variations in the downwelling and total actinic fluxes were about $11 \%$ over the area.

- For overcast situations, 1-D radiative transfer calculations reproduced the overall behaviour of the actinic flux measured by the aircraft. Especially, the 
above-cloud enhancement and below-cloud reductions are well characterized.

- The above-cloud enhancement increases with increasing optical depth. Similarily, the below-cloud reduction increases with increasing optical depth.

- Just below the cloud top, the downwelling actinic flux has a maximum, which is seen in both the measurements and the model results.

- For broken-cloud situations, the cloud fraction approach captures some of the changes in the actinic flux. However, no single value for the cloud fraction is able to reproduce the measured above-cloud enhancement and below-cloud reductions for the analysed situations.

Thus, we conclude that for the cases studied here, cloudless and overcast single-layered clouds may be satisfactorily simulated by $1-\mathrm{D}$ radiative transfer models. The relatively simple broken-cloud cases investigated indicate that for these cloud situations and more-complex cases 3-D corrections must be applied. What these corrections look like is an outstanding research question.

As part of the INSPECTRO project, a second campaign was conducted in May 2004 in southern Germany covering a larger, about $50 \times 50-\mathrm{km}^{2}$, area to further elucidate the impact of clouds on the actinic flux.

Acknowledgements. This research was funded by contract EVK2CT-2001-00130 from the European Commission. Funding by the German Science Foundation (DFG) and the German Research Ministry (BMBF) are acknowledged. Part of this research was performed while one of the authors (M. W.) held a National Research Council Research Associateship Award at the NASA Ames Research Center. As usual the enviscope GmbH company and the pilot of the Partenavia, Bernd Schumacher, did an excellent job in preparing and conducting the measurements with the Partenavia.

Edited by: A. Hofzumahaus

\section{References}

Anderson, G., Clough, S., Kneizys, F., Chetwynd, J., and Shettle, E.: AFGL atmospheric constituent profiles $(0-120 \mathrm{~km})$, Tech. Rep. AFGL-TR-86-0110, Air Force Geophys. Lab., Hanscom Air Force Base, Bedford, Mass., 1986.

Anderson, G. P., Chetwynd, J. H., Theriault, J.-M., Acharya, P. K., Berk, A., Robertson, D. C., Kneizys, F. X., Hoke, M. L., Abreu, L. W., and Shettle, E. P.: MODTRAN2: Suitability for remote sensing, in: Atmospheric Propagation and Remote Sensing, SPIE Conf. Ser., vol. 1968, edited by: Kohnle, A. and Miller, W. B., pp. 514-525, Soc. of Photo-Optical-Instrum. Eng., Bellingham, Wash., 1993.

Bais, A. F., Madronich, S., R., J. C. S., Hall, J., Mayer, B., van Weele, M., G., J. L. J., Calvert, Cantrell, C. A., Shetter, R. E., Hofzumahaus, A., Koepke, P., Monks, P. S., Frost, G., McKenzie, R., Krotkov, N., Kylling, A., Swartz, W. H., Lloyd, S.,
Pfister, G., Martin, T. J., Roeth, E.-P., Griffioen, E., Ruggaber, A., Krol, M., Kraus, A., Edwards, G. D., Mueller, M., Lefer, B. L., Johnston, P., Schwander, H., Flittner, D., Gardiner, B. G., Barrick, J., and Schmitt, R.: International Photolysis Frequency Measurement and Model Intercomparison (IPMMI): Spectral actinic solar flux measurements and modeling, J. Geophys. Res., 108, doi:10.1029/2002JD002 891, 2003.

Barnaba, F. and Gobbi, G.: Modeling the aerosol extinction versus backscatter relationship in a mixed maritime-continental atmosphere: Lidar application and validation, J. Atm. Ocean Technol., 21, 428-442, 2004.

Bass, A. M. and Paur, R. J., The ultraviolet cross-section of ozone, I, The measurements, in: Atmospheric Ozone: Proceedings of the Quadrennial Ozone Symposium, edited by: Zerefos, C. S. and Ghazi, A., pp. 601-606, D. Reidel, Norwell, Mass., 1985.

Brasseur, A.-L., Ramaroson, R., Delannoy, A., Skamarock, W., and Barth, M.: Three-dimensional calculation of photolysis frequencies in the presence of clouds and impact on photochemistry, $\mathrm{J}$. Atmos. Chem., 41, 211-237, 2002.

Cahalan, R. F., Ridgway, W., Wiscombe, W. J., Gollmer, S., and Harshvardhan: Independent pixel and Monte Carlo estimates of stratocumulus albedo, J. Atmos. Sci., 51, 3776-3790, 1994.

Chambers, L. H., Wielicki, B. A., and Evans, K. F.: Accuracy of the independent pixel approximation for satellite estimates of oceanic boundary layer cloud optical depth, J. Geophys. Res., 102, 1779-1794, 1997.

Crawford, J., Shetter, R., Lefer, B., Cantrell, C., Junkermann, W., Madronich, S., and Calvert, J.: Cloud impacts on UV spectral actinic flux observed during the International photolysis frequency measurement and model intercomparison (IPMMI), J. Geophys. Res., 108, doi:10.1029/2002JD002 731, 2003.

Dahlback, A. and Stamnes, K.: A new spherical model for computing the radiation field available for photolysis and heating at twilight, Planet. Space Sci., 39, 671-683, 1991.

de Roode, S. R., Duynkerke, P. G., Boot, W., and der Hage, J. C. H. V.: Surface and tethered-balloon observations of actinic flux: effects of arctic stratus, surface albedo, and solar zenith angle, J. Geophys. Res., 106, 27 497-27 507, 2001.

Evans, K. F., The spherical harmonics discrete ordinate method for three-dimensional atmospheric radiative transfer, J. Atmos. Sci., 55, 429-446, 1998

Früh, B., Trautmann, T., Wendisch, M., and Keil, A.: Comparison of observed and simulated $\mathrm{NO}_{2}$ photodissociation frequencies in a cloudless atmosphere and continental boundary layer clouds, J. Geophys. Res., 105, 9843-9857, 2000.

Früh, B., Eckstein, E., Trautmann, T., Wendisch, M., Fiebig, M., and Feister, U.: Ground-based measured and calculated spectra of actinic flux density and downward UV irradiance in cloudless conditions and their sensitivity to aeosol microphysical properties, J. Geophys. Res., 108, doi:10.1029/2002JD002 933, 2003.

Gobbi, G. P., Barnaba, F., Giorgi, R., and Santacasa, A.: Altituderesolved properties of a Saharan dust event over the Mediterranean, Atmos. Environ., 34, 5119-5127, 2000.

Gobbi, G. P., Barnaba, F., and Ammannato, L.: The vertical distribution of aerosols, Saharan dust and cirrus clouds at Rome (Italy) in the year 2001, Atmos. Chem. Phys., 4, 351-359, 2004,

SRef-ID: 1680-7324/acp/2004-4-351. 
Henderson-Sellers, A. and McGuffie, K.: Are cloud amounts estimated from satellite sensors and conventional surface-based observations related?, Int. J. Remote Sensing, 11, 543-550, 1990.

Hofzumahaus, A., Kraus, A., Kylling, A., and Zerefos, C.: Solar actinic radiation $(280-420 \mathrm{~nm})$ in the cloud-free troposphere between ground and $12 \mathrm{~km}$ altitude: Measurements and model results, J. Geophys. Res., 107, 10.1029/2001JD900 142, 2002.

$\mathrm{Hu}, \mathrm{Y}$. X. and Stamnes, K.: An accurate parameterization of the radiative properties of water clouds suitable for use in climate models, J. Climate, 6, 728-742, 1993.

Jäkel, E., Wendisch, M., Kniffka, A., and Trautmann, T.: A new airborne system for fast measurements of up- and downwelling spectral actinic flux densities, Appl. Opt., 44, 434-444, 2005.

Junkermann, W.: Measurements of the $\mathrm{J}\left(\mathrm{O}^{1} \mathrm{D}\right)$ actinic flux within and above stratiform clouds and above snow surfaces, Geophys. Res. Lett., 21, 793-796, 1994.

Kelley, P., Dickerson, R. R., Luke, W. T., and Kok, G. L.: Rate of $\mathrm{NO}_{2}$ photolysis from the surface to $7.6 \mathrm{~km}$ altitude in clear-sky and clouds, Geophys. Res. Lett., 22, 2621-2624, 1995.

Kylling, A., Bais, A. F., Blumthaler, M., Schreder, J., Zerefos, C. S., and Kosmidis, E.: The effect of aerosols on solar UV irradiances during the Photochemical Activity and Solar Ultraviolet Radiation campaign, J. Geophys. Res., 103, 26 051-26 060, 1998.

Kylling, A., Danielsen, T., Blumthaler, M., Schreder, J., and Johnsen, B.: Twilight tropospheric and stratospheric photodissociation rates derived from balloon borne radiation measurements, Atmos. Chem. Phys., 3, 377-385, 2003a,

SRef-ID: 1680-7324/acp/2003-3-377.

Kylling, A., Webb, A. R., Bais, A. F., Blumthaler, M., Scmitt, R., Thiel, S., Kazantzidis, A., Kift, R., Misslbeck, M., Schallhart, B., Schreder, J., C.Topaloglou, Kazadzis, S., and Rimmer, J.: Actinic flux determination from measurements of irradiance, J. Geophys. Res., 108, doi:10.1029/2002JD003, 236, 2003 b.

Lantz, K. O., Shetter, R. E., Cantrell, C. A., Flocke, S. J., Calvert, J. G., and Madronich, S.: Theoretical, actinometric, and radiometric determinations of the photolysis rate coefficient of $\mathrm{NO}_{2}$ during the Mauna Loa Observatory Photochemistry Experiment 2, J. Geophys. Res., 101, 14 613-14 629, 1996.

Los, A., van Weele, M., and Duynkerke, P. G.: Actinic fluxes in broken cloud fields, J. Geophys. Res., 102, 4257-4266, 1997.

Madronich, S.: Photodissociation in the atmosphere 1. Actinic flux and the effects of ground reflections and clouds, J. Geophys. Res., 92, 9740-9752, 1987.

Matthijsen, J, Suhre, K., Rosset, R., Eisele, F. L., Mauldin III, R. L., and Tanner, D. J.: Photodissociation and UV radiative transfer in a cloudy atmosphere: Modeling and measurements, J. Geophys. Res., 103, 16 665-16676, 1998.

Mayer, B., Seckmeyer, G., and Kylling, A.: Systematic long-term comparison of spectral UV measurements and UVSPEC modeling results, J. Geophys. Res., 102, 8755-8767, 1997.

Mayer, B., and Kylling, A.: Technical note: The libRadtran software package for radiative transfer calculations - description and examples of use, Atmos. Chem. Phys., 5, 1855-1877, 2005,

\section{SRef-ID: 1680-7324/acp/2005-5-1855.}

Mims, F. M. I. and Frederick, J. E.: Cumulus clouds and UV-B, Nature, 371, 291, 1994.

Monks, P. S., Rickard, A. R., Hall, S. L., and Richards, N. A. D., Attenuation of spectral actinic flux and photolysis frequencies at the surface through homogenous cloud fields, J. Geophys. Res.,
109, doi:10.1029/2003JD004 076, 2004.

Nack, M. L. and Green, A. E. S.: Influence of clouds, haze, and smog on the middle ultraviolet reaching the ground, Appl. Opt., 13, 2405-2415, 1974.

Nicolet, M.: On the molecular scattering in the terrestrial atmosphere: An empirical formula for its calculation in the homosphere, Planet. Space Sci., 32, 1467-1468, 1984.

Ramanathan, V., Cess, R. D., Harrison, E. F., Minnis, P., Barkstrom, B. R., Ahmad, E., and Hartmann, D.: Cloud-radiative forcing and climate: results from the Earth radiation budget experiment, Science, 243, 57-63, 1989.

Ruggaber, A., Forkel, R., and Dlugi, R.: Spectral actinic flux and its ratio to spectral irradiance by radiation transfer calculations, J. Geophys. Res., 98, 1151-1162, 1993.

Schwander, H., Koepke, P., and Ruggaber, A.: Uncertainties in modeled UV irradiances due to limited accuracy and availability of input data, J. Geophys. Res., 102, 9419-9429, 1997.

Shetter, R. E. and Müller, M.: Photolysis frequency measurements using actinic flux spectroradiometry during the PEM-Tropics mission: instrumentation description and some results, J. Geophys. Res., 104, 5647-5661, 1999.

Slaper, H., Reinen, H. A. J. M., Blumthaler, M., Huber, M., and Kuik, F.: Comparing ground-level spectrally resolved solar UV measurements using various instruments: A technique resolving effects of wavelengths shift and slit width, Geophys. Res. Lett., 22, 2721-2724, 1995.

Stamnes, K., Tsay, S.-C., Wiscombe, W., and Jayaweera, K.: Numerically stable algorithm for discrete-ordinate-method radiative transfer in multiple scattering and emitting layered media, Appl. Opt., 27, 2502-2509, 1988.

Stamnes, K., Slusser, J., and Bowen, M.: Derivation of total ozone abundance and cloud effects from spectral irradiance measurements, Appl. Opt., 30, 4418-4426, 1991.

Stephens, G. L.: Radiation profiles in extended water clouds. II: Parameterization schemes, J. Atmos. Sci., 35, 2123-2132, 1978.

Stephens, G. L. and Tsay, S.-C.: On the cloud absorption anomaly, Q. J. R. Meteorol. Soc., 116, 671-704, 1990.

Thompson, A. M.: The effect of clouds on photolysis rates and ozone formation in the unpolluted troposphere, J. Geophys. Res., 89, 1341-1349, 1984.

Trautmann, T., Podgorny, I., Landgraf, J., and Crutzen, P. J.: Actinic fluxes and photodissociation coefficients in cloud fields embedded in realistic atmospheres, J. Geophys. Res., 104, $30173-$ $30192,1999$.

Van Weele, M., and Duynkerke, P. G.: Effect of Clouds on the Photodissociation of $\mathrm{NO}_{2}$ : observations and modelling, J. Atmos. Chem., 16, 231-255, 1993.

Van Weele, M. de Arellano, J. V.-G., and Kuik, F.: Combined measurements of UV-A actinic flux, UV-A irradiance and global radiation in relation to photodissociation rates, Tellus, 47B, 353-364, 1995.

Van Weele, M., Martin, T. J., Blumthaler, M., Brogniez, C., den Onter, P. N., Engelsen, O., Lenoble, J., Mayer, B., Pfister, G., Ruggaber, A., Walravens, B., Weihs, P., Gardiner, P. G., Gillotay, D., Haferl, D., Kylling, A., Seckmeyer, G., and Wauben, W. M. F.: From model intercomparison towards benchmark UV spectra for six real atmospheric cases, J. Geophys. Res., 105, 4916-4925, 2000 . 
Várnai, T. and Davies, R.: Effects of cloud heterogeneities on shortwave radiation: comparison of cloud-top variability and internal heterogeneity, J. Atmos. Sci., 56, 4206-4224, 1999.

Vilà-Guerau de Arellano, J., Duynkerke, P. G., and van Weele, M.: Tethered-balloon measurements of actinic flux in a cloud-capped marine boundary layer, J. Geophys. Res., 99, 3699-3705, 1994.

Webb, A. R., Bais, A. F., Blumthaler, M., Gobbi, G.-P., Kylling, A., Schmitt, R., Thiel, S., Barnaba, F., Danielsen, T., Junkermann, W., Kazantzidis, A., Kelly, P., Kift, R., Liberti, G. L., Misslbeck, M., Schallhart, B., Schreder, J., and Topaloglou, C.: Measuring spectral actinic flux and irradiance: Experimental results from the ADMIRA (Actinic Flux Determination from Measurements of Irradiance) Project, J. Atmos. Ocean Technol., 19, 1049-1062, 2002.

Webb, A. R., Kylling, A., Stromberg, I., Jäkel, E., and Wendisch, M.: Airborne measurements of ground and cloud spectral albedo, J. Gepphys. Res., 109D, D20205, doi:10.1029/2004JD004768, 2005.

Weihs, P. and Webb, A. R.: Accuracy of spectral UV model calculations, 1, Consideration of uncertainties in input parameters, J. Geophys. Res., 102, 1541-1550, 1997.
Wendisch, M. and Mayer, B.: Vertical distribution of spectral solar irradiance in the cloudless sky: A case study, Geophys. Res. Lett., 30(4), 1183, doi:10.1029/2002GL016 529, 2003.

Wendisch, M., Müller, D., Schell, D., and Heintzenberg, J.: An airborne spectral albedometer with active horizontal stabilization, J. Atmos. Ocean Technol., 18, 1856-1866, 2001.

Wendisch, M., Pilewskie, P., Jäkel, E., Schmidt, S., Pommier, J., Howard, S., Jonsson, H. H., Guan, H., Schröder, M., and Mayer, B.: Airborne measurements of areal spectral surface albedo over different sea and land surfaces, J. Geophys. Res., 109, D08 203, doi:10.1029/2003JD004 393, 2004.

Woods, T. N., Prinz, D. K., Rottmann, G. J., London, J., Crane, P. C., Cebula, R. P., Hilsenrath, E., Brueckner, G. E., Andrews, M. D., White, O. R., VanHoosier, M. E., Floyd, L. E., Herring, L. C., Knapp, B. G., Pankrantz, C. K., and Reiser, P. A.: Validation of the UARS solar ultraviolet irradiances: Comparison with the Atlas 1 and 2 measurements, J. Geophys. Res., 101, 95419569, 1996. 